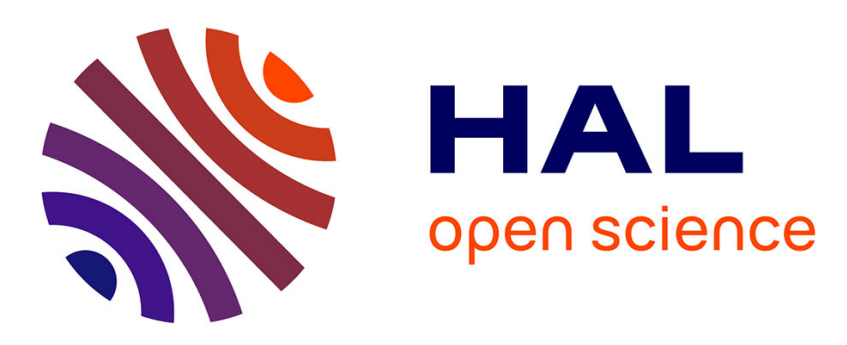

\title{
Synthesis of $\alpha$-aminophosphonate based sorbents - Influence of inserted groups (carboxylic vs. amine) on uranyl sorption
}

\author{
Marwa Rashad, Ibrahim El-Sayed, Ahmed Galhoum, Marwa Abdeen, Hamed \\ Mira, Emad Elshehy, Suojiang Zhang, Xingmei Lu, Jiayu Xin, Eric Guibal
}

\section{To cite this version:}

Marwa Rashad, Ibrahim El-Sayed, Ahmed Galhoum, Marwa Abdeen, Hamed Mira, et al.. Synthesis of $\alpha$-aminophosphonate based sorbents - Influence of inserted groups (carboxylic vs. amine) on uranyl sorption. Chemical Engineering Journal, 2021, 421 (2), pp.127830. 10.1016/j.cej.2020.127830 . hal03095257

\section{HAL Id: hal-03095257 https://hal.mines-ales.fr/hal-03095257}

Submitted on 28 Jan 2021

HAL is a multi-disciplinary open access archive for the deposit and dissemination of scientific research documents, whether they are published or not. The documents may come from teaching and research institutions in France or abroad, or from public or private research centers.
L'archive ouverte pluridisciplinaire HAL, est destinée au dépôt et à la diffusion de documents scientifiques de niveau recherche, publiés ou non, émanant des établissements d'enseignement et de recherche français ou étrangers, des laboratoires publics ou privés. 


\title{
Synthesis of $\alpha$-aminophosphonate based sorbents - Influence of inserted groups (carboxylic $v s$. amine) on uranyl sorption
}

\author{
Marwa M. Rashad a, Ibrahim E. El-Sayed ${ }^{\text {b, }}$, Ahmed A. Galhoum ${ }^{\text {a, }}$, Marwa M. Abdeen ${ }^{\text {, }}$, \\ Hamed I. Mira ${ }^{a}$, Emad A. Elshehy ${ }^{a}$, Suojiang Zhang ${ }^{\text {d,e }}$, Xingmei Lu ${ }^{\text {d,e }}$, Jiayu Xin ${ }^{\text {d,e }}$, \\ Eric Guibal f," \\ ${ }^{a}$ Nuclear Materials Authority, P.O. Box 530, El-Maadi, Cairo, Egypt \\ ${ }^{\mathrm{b}}$ Chemistry Department, Faculty of Science, Menoufia University, Shebin El-Kom, Egypt \\ ${ }^{\mathrm{c}}$ Higher Institute of Engineering and Technology, HIET, Menofia, Egypt \\ ${ }^{\mathrm{d}}$ Beijing Key Laboratory of Ionic Liquids Clean Process, CAS Key Laboratory of Green, Process and Engineering, Institute of Process Engineering, Chinese Academy of \\ Sciences, 100190 Beijing, China \\ e Innovation Academy for Green Manufacture, Institute of Process Engineering, Chinese Academy of Sciences, Beijing 100190, China \\ ${ }^{\mathrm{f}}$ Institut Mines Telecom - Mines Alès, C2MA, Univ. Montpellier, 6 Avenue de Clavières, F-30319 Alès Cedex, France
}

\begin{abstract}
A B S T R A C T
A one-pot synthesis procedure is designed for preparing three $\alpha$-aminophosphonates $\left(\mathrm{R}-\mathrm{H}, \mathrm{R}-\mathrm{COOH}\right.$, and $\mathrm{R}-\mathrm{NH}_{2}$ ); through the reaction of amine precursors (aniline, anthranilic or o-phenylene diamine, respectively) with salicylaldehyde and triphenylphosphite, under controlled conditions. These materials are first characterized by elemental analysis, FTIR, ${ }^{1} \mathrm{H}$ NMR, ${ }^{31} \mathrm{P}$ NMR, BET, DLS, $\mathrm{pH}_{\mathrm{zpc}}$, TGA and titration. In a second step, the sorption properties are compared for $\mathrm{U}(\mathrm{VI})$ recovery from mildly acidic solutions. At the optimum $\mathrm{pH}$ (i.e., $\mathrm{pH} 4$ ) the sorbents can be ranked according the series: $\mathrm{R}-\mathrm{H}\left(1.057 \mathrm{mmol} \mathrm{U} \mathrm{g}{ }^{-1}\right)>\mathrm{R}-\mathrm{NH}_{2}\left(0.746 \mathrm{mmol} \mathrm{U} \mathrm{g}{ }^{-1}\right)>\mathrm{R}-\mathrm{COOH}$ $\left(0.533 \mathrm{mmol} \mathrm{U} \mathrm{g}^{-1}\right)$. The isotherms are fitted by the Langmuir equation. Uranium uptake is relatively fast: under selected experimental conditions, the equilibrium is reached within $90 \mathrm{~min}$ of contact. The kinetic profiles are indistinctly fitted by the model of resistance to intraparticle diffusion and the pseudo-first order rate equation. The study of sorption thermodynamics shows substantial changes between the sorbents: uranyl uptake is endothermic with $\mathrm{R}-\mathrm{H}$ and $\mathrm{R}-\mathrm{NH}_{2}$ sorbents, while the reaction is exothermic with $\mathrm{R}-\mathrm{COOH}$ sorbent. The diversity in functional groups and the speciation of uranyl in sulfuric acid solutions induce metal-binding through a combination of chelation and anion-exchange mechanisms (in function of $\mathrm{pH}$ ). Sodium bicarbonate solutions achieve complete desorption of uranium from loaded-sorbents; the resins can be recycled for a minimum of 4-5 cycles with limited loss in efficiencies. The successful application of these resins for uranium recovery from acidic ore leachates demonstrates their promising properties for valorization of low-grade ores.
\end{abstract}

Keywords:

Uranyl ions

Aminophosphonates

Sorption isotherms

Uptake kinetics

Desorption

Thermodynamics

\section{Introduction}

The interest of research community for uranium recovery is driven by two key parameters. The importance of uranium for nuclear energy production and the near-future shortage of U-bearing resources make the topic economically relevant. In addition, the toxicity of uranium (and associated radionuclides) makes the treatment of effluents and groundwater (or surface waters) a hot environmental topic. Therefore, separation and recovery of uranium are significant for both reasonable utilization of uranium resources (especially low-grade mineralization) and environmental protection [1-5].

Solvent extraction is recognized as an effective and competitive method for the extraction of uranium from concentrated solutions $[6,7]$. For more diluted effluents, sorption processes are more appropriate, including biosorbents [8,9], ion-exchange and chelating resins $[1,3-5,10]$, extractant-impregnated resins $[11]$ because of fast kinetics, environmentally friendliness, good selectivity, high efficiency and reusability.

Many sorbents have been successfully tested for uranium recovery such as inorganic materials (i.e., clay minerals, metal oxides,

\footnotetext{
* Corresponding authors.

E-mail addresses: ibrahimtantawy@yahoo.co.uk (I.E. El-Sayed), Galhoum_nma@yahoo.com (A.A. Galhoum), Eric.Guibal@mines-ales.fr (E. Guibal).
} 
mesoporous silica, metal-organic frameworks) $[1,2,12]$, organic polymers (i.e., resins, cellulose, chitosan) $[3-5,10]$, and carbonaceous materials (i.e., activated carbon, carbon nanotubes, graphene oxides) [4,5]. Chelating resins are polymers bearing specific reactive groups that chelate metal ions. These chelating properties roughly obey the Hard and Soft Acid Base theory (HSAB) developed by Pearson [3-5,10,13]. Uranium is considered a hard acid that shows a higher affinity toward hard bases; therefore, chelating agents bearing $\mathrm{O}, \mathrm{N}$, and $\mathrm{P}$ groups are highly effective for the selective sorption of uranium ions (high capacity, selective separation) $[2-5,10,14,15]$. Particular attention was recently paid to the progress made in designing organophosphorus ligands. Indeed, these compounds have good metal-complexing properties that were widely used in water treatment, for the removal of radioactive and transition metals and for pollution control, at industrial scale $[2-5,16]$. More specifically, aminophosphonates have attracted continuous attention from the research community for the last decades [3,17-21]. However, there is still a need for developing new materials based on this type of chemical structure with selective functionalities, excellent extraction properties and high stability. There is also a need for better understanding how the substituents grafted on the ligand can either promote or degrade sorption performance. In the extraction of uranium from aqueous solutions, both in terms of solvent extraction and sorption on ion-exchange and/or chelating resins, the presence of phosphorus groups (TBP, phosphonate, aminophosphonate) revealed very efficient for the recovery of uranium from aqueous solutions. For this reason, the design of these resins was oriented to the grafting of phosphonate groups. However, the chemical environment of phosphonate groups may change the reactivity of these functional groups due to induction effects, acid-base effects or dual functionalities. This observation motivated the design of these new sorbents and the comparison of their global sorption properties (including desorption and selectivity issues).

This study focuses on the synthesis of a new series of $\alpha$-aminophosphonate-based sorbents. Three derivatives of $\alpha$-aminophosphonate are prepared using a one-pot synthesis procedure and direct reaction of amine precursors with salicylaldehyde and triphenylphosphite. The structure/activity relationship is studied through the evaluation of uranyl sorption properties while varying the chemical environment of grafted amine, from aniline (the "simplest" aromatic amine), to anthranilic (amine ortho-substituted with a carboxylic acid or, o-aminobenzoic acid) and to O-phenylene diamine (ortho-aromatic diamine). The structural and functional characteristics of the three $\alpha$-aminophosphonate derivatives are investigated by elemental analysis, FTIR, ${ }^{1} \mathrm{H}$ NMR, ${ }^{31} \mathrm{P}$ NMR, BET, DLS, TGA, and $\mathrm{pH}_{\mathrm{PZC}}$. Uranium sorption properties are investigated in batch. After $\mathrm{pH}$ optimization, uptake kinetics are investigated and modeled using conventional equations. The sorption isotherms are investigated at different temperatures for evaluating the thermodynamics of $\mathrm{U}(\mathrm{VI})$ sorption. The recycling of the sorbents is investigated along five cycles of sorption and desorption; using sodium bicarbonate solutions as the eluent. In order to evaluate the selectivity of the sorbents, the resins are tested for U(VI) sorption from acidic leachates of polymetallic ore.

\section{Materials and methods}

\subsection{Materials}

Salicylaldehyde, aniline, anthranilic acid, O-phenylene diamine, triphenylphosphite were supplied by Sigma-Aldrich (Saint-Louis, MS, USA). Acetonitrile, and lithium perchlorate were obtained from Fluka AG (Buchs, Switzerland), and all other chemicals were Prolabo products (Prolabo, VWR, Fontenay-sous-Bois, France). Reagents were used as received. Uranium stock solution was prepared from $\mathrm{UO}_{2}(\mathrm{O}-$ $\left.\mathrm{COCH}_{3}\right)_{2} \cdot 2 \mathrm{H}_{2} \mathrm{O}$ (supplied by Sigma Aldrich, Saint-Louis, MS, USA); the salt was dissolved in concentrated sulfuric acid under heating before being diluted with demineralized water until reaching the final concentration of $1000 \mathrm{mg} \mathrm{U} \mathrm{L}^{-1}$. The working solutions were prepared by appropriate dilution of the stock solution immediately prior to use. Uranium concentration was determined using Arsenazo III colorimetric method [22] and a UV-Visible spectrophotometer (Metertech Inc, model SP-8001, Taipei, Taiwan).

\subsection{Synthesis of sorbents}

Scheme 1 shows the synthesis route for the preparation of the resins, while Scheme 2 gives their suggested structures. Amine (aniline/ or Ophenylenediamine / or anthranilic acid) $(1 \mathrm{mmol})$, salicylaldehyde (1 mmol), and triphenylphosphite $(1 \mathrm{mmol})$ were dissolved in $\mathrm{CH}_{3} \mathrm{CN}$ (5 $\mathrm{mL}$ ). The mixture was stirred at room temperature for $10 \mathrm{~min}$ before the Lewis acid catalyst (i.e., $\mathrm{LiClO}_{4}, 20 \mathrm{mg}$ ) was added, at once. The mixture was stirred at room temperature for 3 days [3]. The final products were collected by filtration, washed with acetonitrile and then air-dried to produce the corresponding $\alpha$-aminophosphonates. In order to purify the materials, the solids were recrystallized after being dispersed in chloroform or methanol. Finally, the dried powders were stored in a desiccator, before use.

\subsection{Characterization of materials}

The elemental analysis (C, H, N) was determined using an automatic analyzer (CHNS Vario EL III-elementar analyzer, Elementar, Germany), at the Micro Analytical Unit (al-Azhar University, Egypt). Phosphorus content was specifically analyzed after chemical digestion in a sulfuric/ nitric solution followed by spectrophotometric analysis (absorbance measured at $\lambda: 410 \mathrm{~nm})[23,24]$. The ${ }^{1} \mathrm{H}$ NMR spectrum was recorded at $400 \mathrm{MHz}$ in DMSO- $d_{6}$ using a JEOL ECA-500 II spectrometer (JEOL, Tokyo, Japan) (at Analytical Lab, from Mansoura University, Egypt). ${ }^{31}$ PNMR spectrum was recorded at $162 \mathrm{MHz}$ in DMSO- $d_{6}$ using a BRUKER spectrometer (JEOL, Tokyo, Japan) (at Analytical Lab, from Zagazig University, Egypt). The FTIR spectra were directly obtained, in the wavenumber range $4000-400 \mathrm{~cm}^{-1}$, using a ThermoFisher Nicolet IS10 (Waltham, MA, USA spectrometer) (at Analytical Lab, from Mansoura University, Egypt). TG/DTA analyses were recorded using a thermogravimetric and differential thermal analyzer EXSTAR 6000 TG/ DTA $6300 \mathrm{~N}$ (Seiko Instruments Inc. (SII), Chiba, Japan). Experiments were performed under $\mathrm{N}_{2} / \mathrm{O}_{2}$ atmosphere, within the temperature range $20-1000{ }^{\circ} \mathrm{C}$ and at the ramp rate of $10^{\circ} \mathrm{C} / \mathrm{min}$. Surface area and pore volume were determined from nitrogen adsorption-desorption isotherms using a Quantachrome Nova 3200 instrument (Quantachrome Instruments, Boynton Beach, FL, USA). The specific surface area and porous characteristics of sorbents were obtained by BET method and $\mathrm{BJH}$ method, respectively, under a degassing temperature of $80^{\circ} \mathrm{C}$ for 3 h using a Belsorp-Max II (Microtrac BEL, now Microtrac MRB, Haan, Germany). The size distribution and zeta-potential of the nanocomposite were determined by diffraction light scattering using a Zetasizer Nano ZS (Malvern Instruments Ltd., Malvern, UK). The $\mathrm{pH}$ at zero-charge $\left(\mathrm{pH}_{\mathrm{PZC}}\right)$ of the three resins was determined by the $\mathrm{pH}$-drift method [25]: the resins were mixed, for $24 \mathrm{~h}$, with a series of $0.1 \mathrm{M} \mathrm{NaCl}$ solutions at different $\mathrm{pH}$ values $\left(\mathrm{pH}_{0}\right)$; the $\mathrm{pH}_{\mathrm{PZC}}$ corresponds to the conditions for unchanged $\mathrm{pH}$ (i.e., $\mathrm{pH}_{0}=\mathrm{pH}_{\mathrm{eq}}$, equilibrium $\mathrm{pH}$ ).

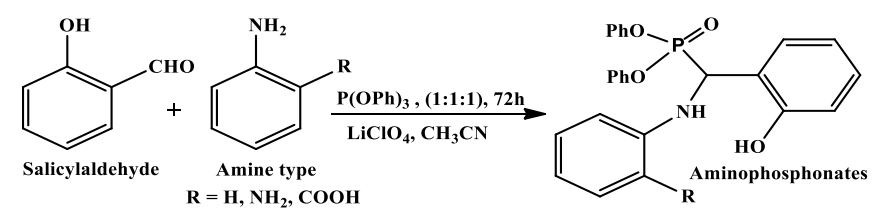

Scheme 1. Schematic route for the synthesis of $\alpha$-aminophosphonatesbased sorbents. 


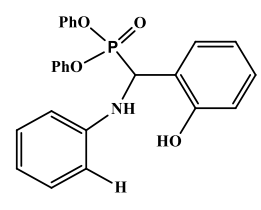

Aniline-based

sorbent (R-H)
Anthranilic-based sorbent (R-COOH)

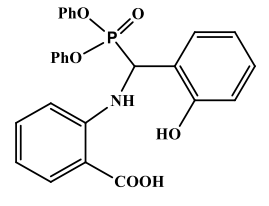

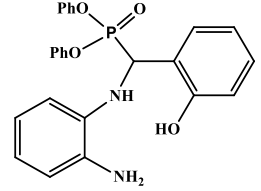

O-phenylenediamine-based sorbent (R-NH2)
Scheme 2. Structure of aniline-, anthranilic-, and o-phenylenediaminebased sorbents.

\subsection{Sorption and desorption experiments}

Batch experiments were carried out by contact of a mass of sorbent $(\mathrm{m}, \mathrm{g})$ with a fixed volume $(\mathrm{V}, \mathrm{L})$ of aqueous metal-containing solution $\left(\mathrm{C}_{0}, \mathrm{mmol} \mathrm{U} \mathrm{L}^{-1}\right)$, at initial $\mathrm{pH}$ value $\left(\mathrm{pH}_{0}\right)$ in a conical flask. The sorbent dosage, $\mathrm{SD}=\mathrm{m} / \mathrm{V}$ was set, unless specified, at $0.5 \mathrm{~g} \mathrm{~L}^{-1}$. The flasks were maintained for $3 \mathrm{~h}$ under agitation (200 rpm), at room temperature (i.e., $\mathrm{T}$ : $25 \pm 1{ }^{\circ} \mathrm{C}$ ). After equilibration and phase separation (filtration through $1.2 \mu \mathrm{m}$ pore-size filter membrane), the residual uranium concentration in the aqueous phase $\left(\mathrm{C}_{\mathrm{eq}}, \mathrm{mmol} \mathrm{U} \mathrm{L}^{-1}\right)$ was determined. The concentration of uranium in the sorbent $\left(\mathrm{q}_{\mathrm{eq}}, \mathrm{mmol} \mathrm{U} \mathrm{g}^{-1}\right.$ ) was calculated by the mass balance equation, $\mathrm{q}_{\mathrm{eq}}=\left(\mathrm{C}_{0}-\mathrm{C}_{\mathrm{eq}}\right) \times \mathrm{V} / \mathrm{m}$. The distribution ratio, $\mathrm{D}\left(\mathrm{L} \mathrm{g}^{-1}\right)$, corresponds to $\mathrm{D}=\mathrm{q}_{\mathrm{eq}} / \mathrm{C}_{\mathrm{eq}}$. The $\mathrm{pH}$ was not adjusted during the sorption step but the equilibrium $\mathrm{pH}$ was recorded.

Isotherm studies were investigated by mixing $0.01 \mathrm{~g}$ of sorbent with $20 \mathrm{~mL}$ of $\mathrm{U}(\mathrm{VI})$ solution at different initial concentrations (i.e., $0.1-1.30$ mmol $\mathrm{U} \mathrm{L}^{-1}$, at $\mathrm{pH} 4$ ) and shaking for $2 \mathrm{~h}$ at $200 \mathrm{rpm}$. Uptake kinetics was performed using a sorbent dosage of $0.5 \mathrm{~g} \mathrm{~L}^{-1}$ and a concentration of $0.323 \mathrm{mmol} \mathrm{U} \mathrm{L}^{-1}$ at $298 \mathrm{~K}$ : samples were collected under agitation at fixed contact times. The residual metal concentration was determined, after phase separation.

Standard experimental conditions were set at T: $25 \pm 1{ }^{\circ} \mathrm{C}$ and pH: 4 \pm 0.01 ; the contact time was fixed to $2 \mathrm{~h}$. Preliminary studies have shown that an extended contact time (extended up to $24 \mathrm{~h}$ ) dids not significantly change sorption performance. Sodium bicarbonate 0.05 $\mathrm{M})$ and $\mathrm{HCl}(0.1 \mathrm{M})$ solutions were initially tested for uranium desorption; the two eluents showed comparable desorption efficiencies. Being less aggressive, sodium bicarbonate $(0.05 \mathrm{M})$ was chosen as the eluent for the continuation of the study of metal desorption. The contact time between the eluent and the metal-loaded sorbent was set to $90 \mathrm{~min}$ (under constant agitation). The sorption yield after regeneration for four additional cycles was compared to the value reached for the first cycle. The desorption efficiency (DE) (i.e., $\mathrm{DE}=\mathrm{C}_{\mathrm{D}} \times \mathrm{V} \times 100 / \mathrm{q}_{\mathrm{d}} \times \mathrm{m}$ ) and regeneration rate $(R E)$ (i.e., $R E=q_{d} \times 100 / q_{e}$ ) were calculated; where $\mathrm{C}_{\mathrm{D}}\left(\mathrm{mmol} \mathrm{U} \mathrm{L}^{-1}\right)$ is $\mathrm{U}(\mathrm{VI})$ concentration in eluate; $\mathrm{q}_{\mathrm{d}}\left(\mathrm{mmol} \mathrm{U} \mathrm{g}^{-1}\right)$ is the sorption capacity for metal loaded material (before desorption experiment), $\mathrm{q}_{\mathrm{e}}$ (mmol $\mathrm{U} \mathrm{g}^{-1}$ ) is the sorption capacity at the first cycle. The distribution of the particle sizes of the different sorbents (analyzed by DLS) showed that the smallest particles can pass through the membranes. However, the side-aggregation (facilitated by the hydroxyl groups on the sorbents) may contribute to side-aggregation that artificially grows the particle size while operating sorption. Actually, the weight loss at the first step was evaluated close to $3 \%$, while it was negligible (below 1\%) for the next cycles. This weak weight loss of sorbent can partially contribute to the slight decrease in sorption performance at sorbent recycling.

The fitting of uptake kinetics and sorption isotherms has been performed using conventional equations that are summarized in Table AM1 (see Additional Material Section). Parameters were obtained by nonlinear regression analysis using Mathematica ${ }^{\circledR}$ software facilities.

\subsection{Application to acidic ore leachate}

The ore was collected on the site of El-Sella (Southern Eastern Desert, Egypt). This site is located Latitudes $22^{\circ} 14^{\prime} 30 / /$ and $22^{\circ} 18^{\prime} 36 / / \mathrm{N}$ and
Longitudes $36^{\circ} 11^{\prime} 45 / /$ and $36^{\circ} 16^{\prime} 30 / / \mathrm{E}$, at a distance of about $60 \mathrm{~km}$ at the southwest of Abu Ramad. Map AM1 (see Additional Material Section) reports the main geological characteristics of this site. According to Ibrahim et al. [26], it is essentially composed of potashfeldspar, plagioclase, muscovite and biotite. Secondary minerals are sericite, kaolinite and chlorite. The uranium mineralization is mainly of the oxidized type where it consists essentially of secondary uranium minerals: uranophane, $\beta$-uranophane and $B$-autunite (uranium phosphate mineral, $\left(\mathrm{Ca}\left(\mathrm{UO}_{2}\right)_{2}\left(\mathrm{PO}_{4}\right)_{2} \cdot 10-12 \mathrm{H}_{2} \mathrm{O}\right)$. Autunite is mainly observed in shear zones, in addition to uranophane and betauranophane. Secondary uranium minerals occur either disseminated or as cavity filling. Some accessory minerals, such as monazite, fluorite and apatite, which are considered as the main sources for REEs $[3,26,27]$, have also been identified. Table AM2 reports the main constituents of the ore. The major oxides in the ore were quantified by the procedure of rapid silicate analysis [28]: the ore was dissolved in alkaline solution for $\mathrm{SiO}_{2}$ determination and in an acid solution for the determination of $\mathrm{MgO}, \mathrm{TiO}_{2}, \mathrm{CaO}, \mathrm{Al}_{2} \mathrm{O}_{3}, \mathrm{P}_{2} \mathrm{O}_{5}, \mathrm{Fe}_{2} \mathrm{O}_{3}$ oxides (etc.). Other elements were obtained by spectrophotometry ( $\mathrm{Si}, \mathrm{Al}, \mathrm{P}, \mathrm{Mn}, \mathrm{Ti}$ ), titration $(\mathrm{Mg}, \mathrm{Ca}, \mathrm{Fe})$ or atomic absorption spectrometry (Na, K) [28].

Acidic leaching was processed in batch reactor after grinding the mineral and sieving the fraction below 100 mesh $(149 \mu \mathrm{m})$. Sulfuric acid $\left(50 \mathrm{~g} \mathrm{~L}^{-1}, \sim 0.51 \mathrm{~mol} \mathrm{~L}^{-1}\right)$ was mixed with grinded ore at $50{ }^{\circ} \mathrm{C}$ for $6 \mathrm{~h}$; the solid/liquid ratio was set at 1:3. After leaching operation, the ore was washed with demineralized water and the washing water was mixed with leachate to produce pregnant leaching solution (PLS). Metal concentrations in the leachate solution were determined by titration for $\mathrm{U}$ to avoid the interference in spectrophotometry method [29,30]; where, uranium analysis was performed using the oxidimetric titration method against ammonium metavanadate (diphenylamine sulfonate being used as the indicator and uranium was reduced with ammonium ferrous sulfate just prior analysis) [29]. The composition of PLS is summarized in Table AM2. Uranium concentration in the leachate approaches 1026 $\mathrm{mg} \mathrm{U} \mathrm{L}^{-1}$; leaching yield reaches $86 \%$. The $\mathrm{pH}$ of the leachate was 1.98 .

In order to reduce the concentration of iron (by precipitation), the $\mathrm{pH}$ of PLS was raised to 3.5-4. Table AM2 shows the composition of PPLS (partially precipitated PLS).

Sorption test was carried out on PPLS solution with a $\mathrm{pH}$ controlled to 4 and with a sorbent dosage of $0.5 \mathrm{~g} \mathrm{~L}^{-1}$; the suspension was mixed for $3 \mathrm{~h}$, at room temperature (i.e., $25 \pm 1{ }^{\circ} \mathrm{C}$ ). The filtrated sample was analyzed for residual concentrations using atomic absorption spectrometer (Solar Unicam 969 AAS, Thermo Scientific, Waltham, MA, USA).

Annex (see Additional Material section, AMS) shows the reproducibility of sorption performances for $\mathrm{pH}$ effect, uptake kinetics, sorption isotherms and sorbent recycling. The replicates show good reproducibility and the largest differences were reported for R-COOHG (tests having been performed with another production of $\mathrm{R}-\mathrm{COOH}$ sorbent, new stock).

\section{Results and discussion}

\subsection{Synthesis and characterization of new aminophosphonate sorbents}

Scheme 1 illustrates the synthesis route for the preparation of $\alpha$-aminophosphonates. This simple one-pot reaction occurs between amine compounds (whatever the precursor) and both salicylaldehyde and triphenylphosphite; $\mathrm{LiClO}_{4}$ is used as the catalyst for the conversion into resins (with tentative structures represented on Scheme 2). Scheme AM1 (see Additional Material Section) shows the suggested mechanisms for the molecular interactions between the reagents for producing $\mathrm{R}-\mathrm{H}$ (aniline precursor); similar process is suggested for the other substitutions. The first step consists of the formation of an imineintermediate, followed by the attack of this intermediate by nucleophilic phosphite (leading to the formation of phosphonium ion). This reaction is catalyzed by the presence of the Lewis acid catalyst (i.e., 
$\mathrm{LiClO}_{4}$ ). In the last step of the process, the reaction of phosphonium intermediates with water promotes the elimination of phenol and the formation of the relevant $\alpha$-aminophosphonates (Scheme AM1). This interpretation of resin synthesis is supported by a series of analyses (see below).

Based on the quantities of reagents and the effective amounts of products synthesized it was possible evaluating the yields to:

(a) $78.0 \%$ for R-H (i.e., $2.69 \mathrm{~g}$ for $3.45 \mathrm{~g}$, the limiting agent is aniline),

(b) $76.0 \%$ for R-COOH (i.e., $2.95 \mathrm{~g}$ for $3.88 \mathrm{~g}$, the limiting agent is 2 aminobenzoic acid), and

(c) $77.1 \%$ for $\mathrm{R}^{-\mathrm{NH}_{2}}$ (i.e., $2.82 \mathrm{~g}$ for $3.66 \mathrm{~g}$, the limiting agent is salicylaldehyde).

\subsubsection{Elemental analysis}

The elemental analysis of the $\alpha$-aminophosphonate derivatives confirms the effectiveness of the reaction between amine-bearing compounds and triphenylphosphite: the presence of both $\mathrm{N}$ and $\mathrm{P}$ elements demonstrates the formation of aminophosphonate (Table 1).

The $\mathrm{P}$ content (weight percentage) in the sorbents is: $7.75 \%, 7.25 \%$ and $7.59 \%$ (i.e., $2.50 \mathrm{mmol} \mathrm{P} \mathrm{g}$, $2.34 \mathrm{mmol} \mathrm{P} \mathrm{g}^{-1}$ and $2.45 \mathrm{mmol} \mathrm{P}$ $\mathrm{g}^{-1}$, respectively) for $\mathrm{R}-\mathrm{H}, \mathrm{R}-\mathrm{COOH}$ and $\mathrm{R}^{-\mathrm{NH}_{2}}$, respectively. Theoretical molecular formula and weight of investigated $\alpha$-aminophosphonate derivatives were proposed, as follows for aniline-derivative (R-H; M.F.: $\mathrm{C}_{25} \mathrm{H}_{22} \mathrm{NO}_{4} \mathrm{P}$ ), anthranilic acid-derivative (R-COOH; M.F.: $\mathrm{C}_{26} \mathrm{H}_{22} \mathrm{NO}_{6} \mathrm{P}$ ), and o-phenylenediamine-derivative (R- $\mathrm{NH}_{2} ; \quad$ M.F.: $\mathrm{C}_{25} \mathrm{H}_{23} \mathrm{~N}_{2} \mathrm{O}_{4} \mathrm{P}$ ). Chemical structures were drawn using ChemBioDraw ultra, v.12.0. The supposed chemical formulae are reported in Table 1, with the corresponding molecular weights and the expected mass fractions for the different elements. The molecular weights increase for the different derivatives according to: $\mathrm{R}-\mathrm{H}\left(431.42 \mathrm{~g} \mathrm{~mol}^{-1}\right)<\mathrm{R}^{-\mathrm{NH}_{2}}(446.43 \mathrm{~g}$ $\mathrm{mol}^{-1}$ ) $<\mathrm{R}-\mathrm{COOH}\left(475.43 \mathrm{~g} \mathrm{~mol}^{-1}\right.$ ). This means that in $1 \mathrm{~g}$ of sorbent, the theoretical number of mmoles follows the reverse ranking: $\mathrm{R}-\mathrm{COOH}$ $(2.103 \mathrm{mmol})<\mathrm{R}^{-N_{2}}(2.224 \mathrm{mmol})<\mathrm{R}-\mathrm{H}(2.318 \mathrm{mmol})$. The $\mathrm{P}$ content is roughly consistent with the stoichiometry of the theoretical molecular formula for the different sorbents: R-H sorbent (i.e., $1.08 \mathrm{~mol}$ $\mathrm{P}$ per mol of resin), R-COOH (i.e., $1.11 \mathrm{~mol} \mathrm{P}$ per $\mathrm{mol}$ of resin) and $\mathrm{R}-\mathrm{NH}_{2}$ (i.e., $1.10 \mathrm{~mol} \mathrm{P}$ per mol of resin). It is noteworthy that the fraction of nitrogen exceeds the expected percentages: compared to expected structure, the excess represents from $36 \%$ to $61 \%$ depending on the resin. On the other hand, the fractions of $\mathrm{C}$ and $\mathrm{H}$ are generally lower than expected, with the remarkable exception of $\mathrm{H}$ in $\mathrm{R}-\mathrm{NH}_{2}$ that shows a higher $\mathrm{H}$ content than in the theoretical formula. These discrepancies may be associated to the impact of moisture fraction and to the release of constitutive (bound) water.

\subsubsection{Fourier transform infrared spectroscopy (FTIR)}

FTIR spectroscopy was used for characterizing the functional groups on the sorbent (Fig. 1) and their interactions with uranyl ions $\left(\mathrm{UO}_{2}^{2+}\right)$ (Figs. 2). The reaction of salicylaldehyde with triphenylphosphite leads to the formation of $\alpha$-aminophosphonate, which is confirmed by the appearance of specific peaks on FTIR spectra, especially assigned to Pbased reactive groups. For example, three series of peaks are identified:
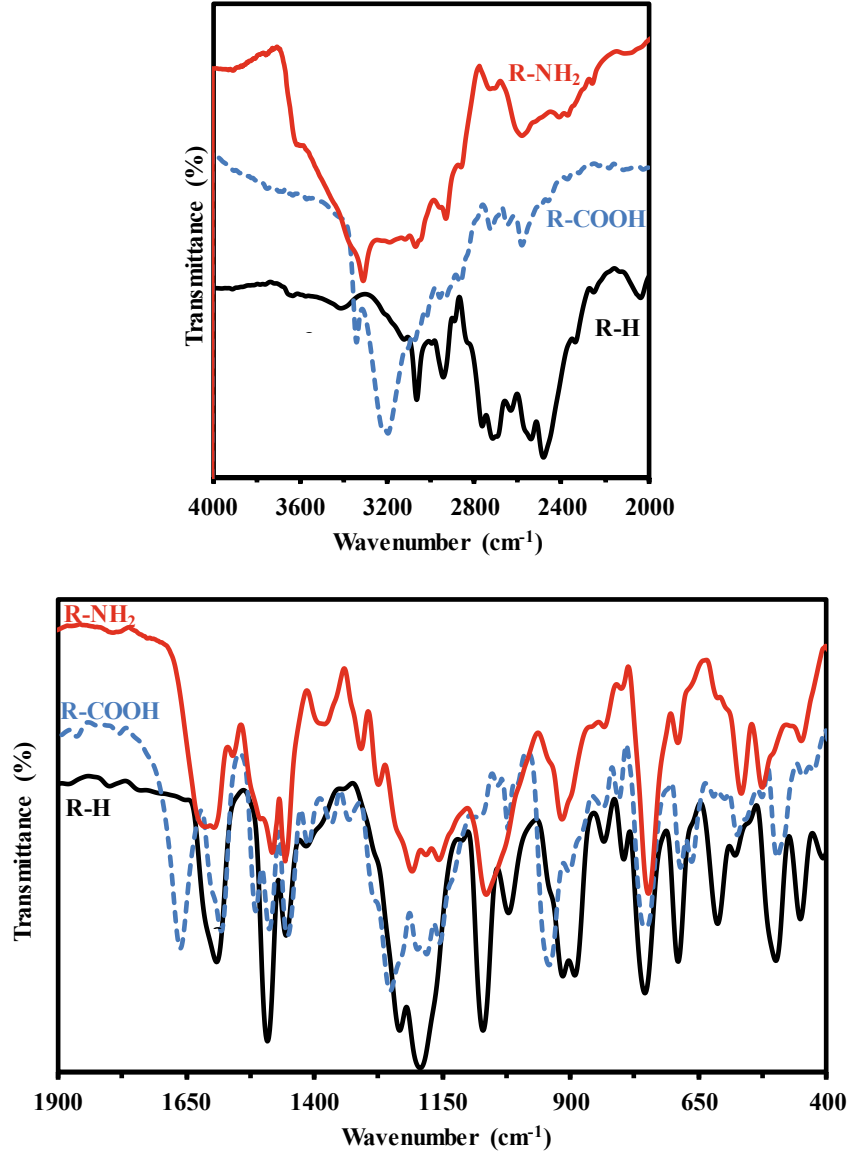

Fig. 1. FTIR spectra of R-H, R-COOH, and $\mathrm{R}-\mathrm{NH}_{2}$ sorbents.

(a) at $1210-1253 \mathrm{~cm}^{-1}$ for $\mathrm{v}(-\mathrm{P}=0)[16,31,32]$,

(b) at $916-943 \mathrm{~cm}^{-1}$ for $\mathrm{v}(\mathrm{P}-\mathrm{O}-\mathrm{C})$ [31-35],

(c) at $749-756 \mathrm{~cm}^{-1}$ for $\mathrm{P}-\mathrm{CH}$ bond.

The sharp peak at $1070 \mathrm{~cm}^{-1}$ is assigned to $\mathrm{C}=\mathrm{O}$ bond. In addition, the broad band centered around $1592-1662 \mathrm{~cm}^{-1}$, which is assigned to $\mathrm{C}=\mathrm{C}$ bond in aromatic rings, and the peak at $690 \mathrm{~cm}^{-1}$, attributed to $v$ (phenyl group) [3], demonstrate the effective reaction of the substrates to form the aminophosphonate resins.

Based on the tentative structures of the $\alpha$-aminophosphonate derivatives depicted on Scheme 2, the groups the most significant for the identification of the different compounds can be reported, as follows.

For aniline-based derivative (i.e., R-H resin), the broad band observed between 2888 and $3119 \mathrm{~cm}^{-1}$ corresponds to the overlapping of $v(-\mathrm{NH})$ and $\mathrm{v}(-\mathrm{OH})$ vibrations. In the case of anthranilic derivative (i.e., R-COOH), a typical carbonyl vibration (i.e., $\mathrm{v}\left(-\mathrm{COO}^{-}\right)$or $\mathrm{v}(-\mathrm{C}=\mathrm{O})$ ) appears at $1662 \mathrm{~cm}^{-1}$ [35]. For the amino derivative (i.e., R$\mathrm{NH}_{2}$ ), the grafting of o-phenylenediamine is correlated to the broad overlapping of stretching vibrations associated with $-\mathrm{NH},-\mathrm{OH}$ and $-\mathrm{NH}_{2}$ groups in the range $2858-3420 \mathrm{~cm}^{-1}[16,36]$. In addition, the intensities of signals associated to primary and secondary amine groups

Table 1

CHNP analysis of the three sorbents $(\mathrm{R}-\mathrm{H}),(\mathrm{R}-\mathrm{COOH})$ and $\left(\mathrm{R}-\mathrm{NH}_{2}\right)$ (Calculated: calc.; Found results).

\begin{tabular}{|c|c|c|c|c|c|c|c|c|c|c|c|c|}
\hline \multirow[t]{2}{*}{ Sample } & \multicolumn{2}{|l|}{$\mathrm{C}(\%)$} & \multicolumn{2}{|l|}{$\mathrm{H}(\%)$} & \multicolumn{2}{|l|}{$\mathrm{N}(\%)$} & \multicolumn{2}{|l|}{$\mathrm{P}(\%)$} & \multicolumn{2}{|l|}{$\mathrm{O}(\%)^{*}$} & \multirow[t]{2}{*}{$\mathrm{MW}\left(\mathrm{g} \mathrm{mol}^{-1}\right)$} & \multirow[t]{2}{*}{ Chemical Formula } \\
\hline & Found & Calc. & Found & Calc. & Found & Calc. & Found. & Calc. & Found & Calc. & & \\
\hline R-H & 63.92 & 69.54 & 4.03 & 5.10 & 4.94 & 3.25 & 7.754 & 7.19 & 19.36 & 14.83 & 431.42 & $\mathrm{C}_{25} \mathrm{H}_{22} \mathrm{NO}_{4} \mathrm{P}$ \\
\hline $\mathrm{R}-\mathrm{COOH}$ & 61.16 & 65.62 & 3.62 & 4.63 & 4.01 & 2.94 & 7.246 & 6.52 & 23.97 & 20.19 & 475.43 & $\mathrm{C}_{26} \mathrm{H}_{22} \mathrm{NO}_{6} \mathrm{P}$ \\
\hline $\mathrm{R}-\mathrm{NH}_{2}$ & 62.79 & 67.20 & 5.63 & 5.15 & 5.02 & 6.27 & 7.589 & 6.94 & 18.98 & 14.34 & 446.43 & $\mathrm{C}_{25} \mathrm{H}_{23} \mathrm{~N}_{2} \mathrm{O}_{4} \mathrm{P}$ \\
\hline
\end{tabular}

*: obtained by difference to $100 \%$ (w/w fraction). 


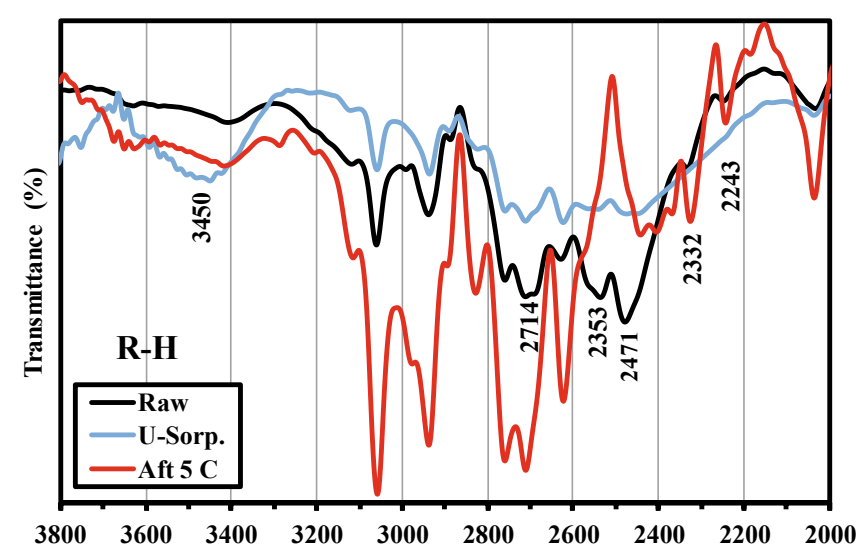

Wavenumber $\left(\mathrm{cm}^{-1}\right)$

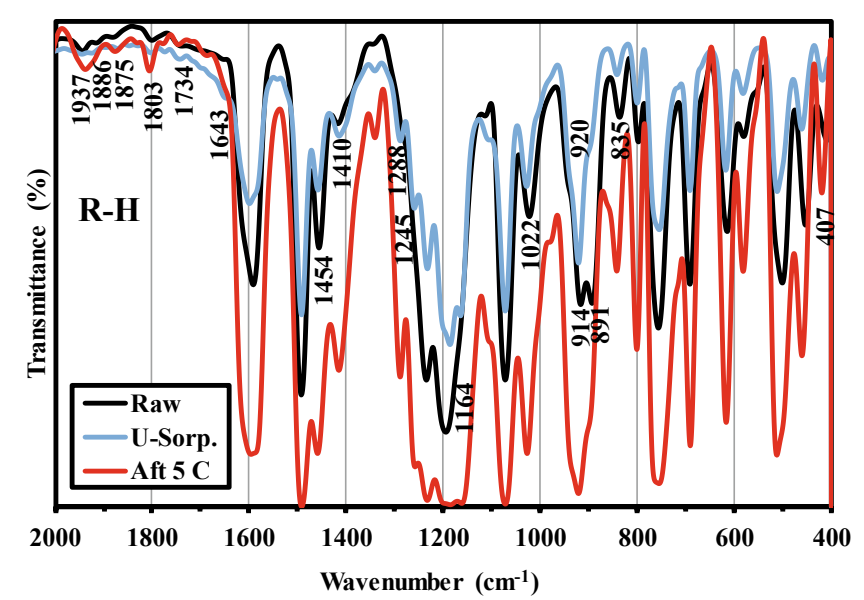

Fig. 2a. FTIR spectra of R-H before (raw) and after U(VI) sorption (U-Sorp.) and after 5 cycles of sorption and desorption (Aft.5C).

increase at $1300-1500 \mathrm{~cm}^{-1}$ and $1600 \mathrm{~cm}^{-1}$, respectively [16].

FTIR analysis was performed before and after uranyl ion $\left(\mathrm{UO}_{2}^{2+}\right)$ sorption; Figure AM1 (see Additional Material Section) shows some changes in terms of relative intensity of some bands, appearance and disappearance of valleys and shift of wavenumbers for some specific bands. The changes in the region $2218-3639 \mathrm{~cm}^{-1}$ can be directly associated with the binding of metal ions, which, in turn, affects the environment of $\mathrm{OH}$ and $\mathrm{NH}$ groups [16,37]. The peaks at 1186-1251 $\mathrm{cm}^{-1}$ and $919-932 \mathrm{~cm}^{-1}$, which are assigned to $\mathrm{v}(-\mathrm{P}=\mathrm{O}), \mathrm{v}(\mathrm{P}-\mathrm{OH})$ and $\mathrm{v}(\mathrm{P}-\mathrm{O}-\mathrm{C})$ vibrations, are shifted and their relative intensity tends to decrease (almost disappearing) after uranyl sorption [37]. The changes of the absorption peaks in this fingerprint region show that phosphonate functional groups contribute to uranyl sorption.

For R-H sorbent (Fig. 2a), the most substantial changes concern: (a) the appearance of new peaks at $1288 \mathrm{~cm}^{-1}, 1245 \mathrm{~cm}^{-1}$ and $1164 \mathrm{~cm}^{-1}$, (b) the disappearance of the peak at $891 \mathrm{~cm}^{-1}$, and (c) the shift of the peak at $405 \mathrm{~cm}^{-1}$ (to $416 \mathrm{~cm}^{-1}$ ). For R-COOH (Fig. 2b), after U(VI) sorption the shoulder at $1234 \mathrm{~cm}^{-1}$ disappears, the peaks in the region $1211-1142 \mathrm{~cm}^{-1}$ are affected by metal binding (decrease of relative intensities at $1204 \mathrm{~cm}^{-1}$ and $1157 \mathrm{~cm}^{-1}$ ), while the peak at $935 \mathrm{~cm}^{-1}$ is split into two peaks at $966 \mathrm{~cm}^{-1}$ and $932 \mathrm{~cm}^{-1}$. The shoulders at 1597 $\mathrm{cm}^{-1}$ and $1712 \mathrm{~cm}^{-1}$ (carboxylate and carboxylic groups, respectively [38]) is smoothed after $\mathrm{U}(\mathrm{VI})$ binding. The intensity of the peak at $\approx$ $573 \mathrm{~cm}^{-1}$ substantially increases while the peak at $426 \mathrm{~cm}^{-1}$ disappears. In the case of $\mathrm{R}-\mathrm{NH}_{2}$ (Fig. 2c), the differences are poorly marked. The poorly-resolved large band in the region $1640-1580 \mathrm{~cm}^{-1}$ is characterized by two wavenumbers at $1614 \mathrm{~cm}^{-1}$ and $1597 \mathrm{~cm}^{-1}$ (with the lowest transmittance); after $\mathrm{U}(\mathrm{VI})$ sorption, the peak at $1597 \mathrm{~cm}^{-1}$
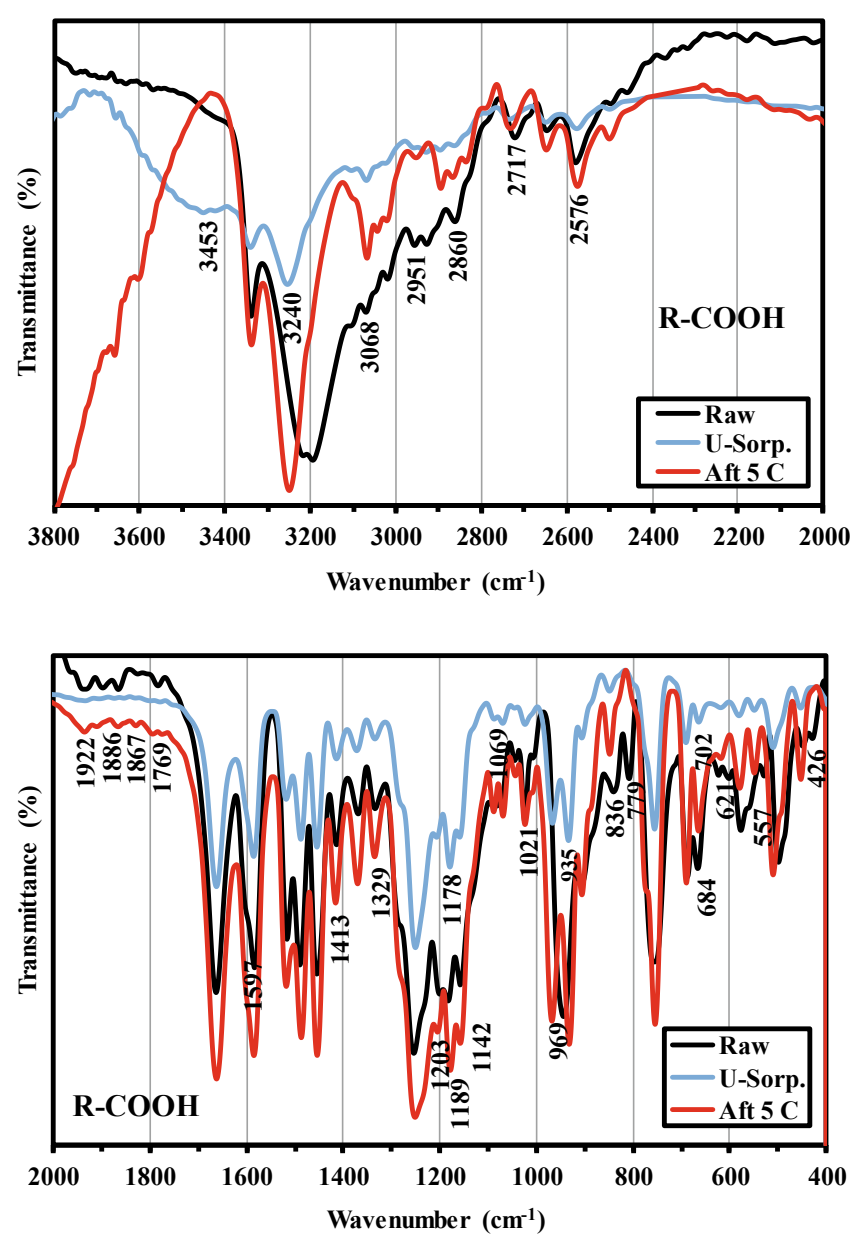

Fig. 2b. FTIR spectra of R-COOH before (raw) and after U(VI) sorption (USorp.) and after 5 cycles of sorption and desorption (Aft.5C).

decreases in intensity (appearing as a shoulder) and the width of the band is increased. Some weak shifts and changes in relative intensities are also observed in the range $1415-1329 \mathrm{~cm}^{-1}$ (decrease of the $1385-1365 \mathrm{~cm}^{-1}$ contribution after metal sorption). The sorption of $\mathrm{U}$ (VI) shows significant differences in terms of modification of FTIR spectra: this confirms that the change in substituents affects the mechanism of metal binding. Apart phosphonate groups, whose typical Pbased bands around 1250-1180 $\mathrm{cm}^{-1}$ and $940-900 \mathrm{~cm}^{-1}$ are affected, the environmental of specific groups are also modified by metal uptake: carbonyl groups for R-COOH (carboxylic/carboxylate groups in the range $1720-1580 \mathrm{~cm}^{-1}$, [38]) or amino groups $\left(1650-1590 \mathrm{~cm}^{-1}\right.$, [38]). It is noteworthy that many studies reveal the presence of a specific band on sorbents loaded with uranyl ions at $\approx 900 \mathrm{~cm}^{-1}$ [39]; on these spectra the peak is difficult to detect; this is probably due to the overlapping with other signals around.

The sorbents were also analyzed after five cycles of sorption and desorption in order to assess their stability when exposed to different types of solutions (sorption at $\mathrm{pH} 4$ and desorption in sodium bicarbonate solutions, see below). Figs. 2 shows that the step of desorption partially restores the FTIR spectra of the sorbents. However, it is noteworthy that many tracer bands of metal sorption remain on the FTIR spectra of regenerated sorbents, which can be considered as "intermediary" spectra between raw and metal-loaded sorbents. For example, in the case of R-H in the regions around $2500 \mathrm{~cm}^{-1}$ or $500-400 \mathrm{~cm}^{-1}$, the spectrum is not fully restored. The peaks at $1289 \mathrm{~cm}^{-1}$ and $893 \mathrm{~cm}^{-1}$ are also emblematic examples of the differences between raw and regenerated R-H sorbent. For R-COOH, many bands also show that desorption cannot restore the spectrum, especially in the regions: $3400-3100 \mathrm{~cm}^{-1}$ 

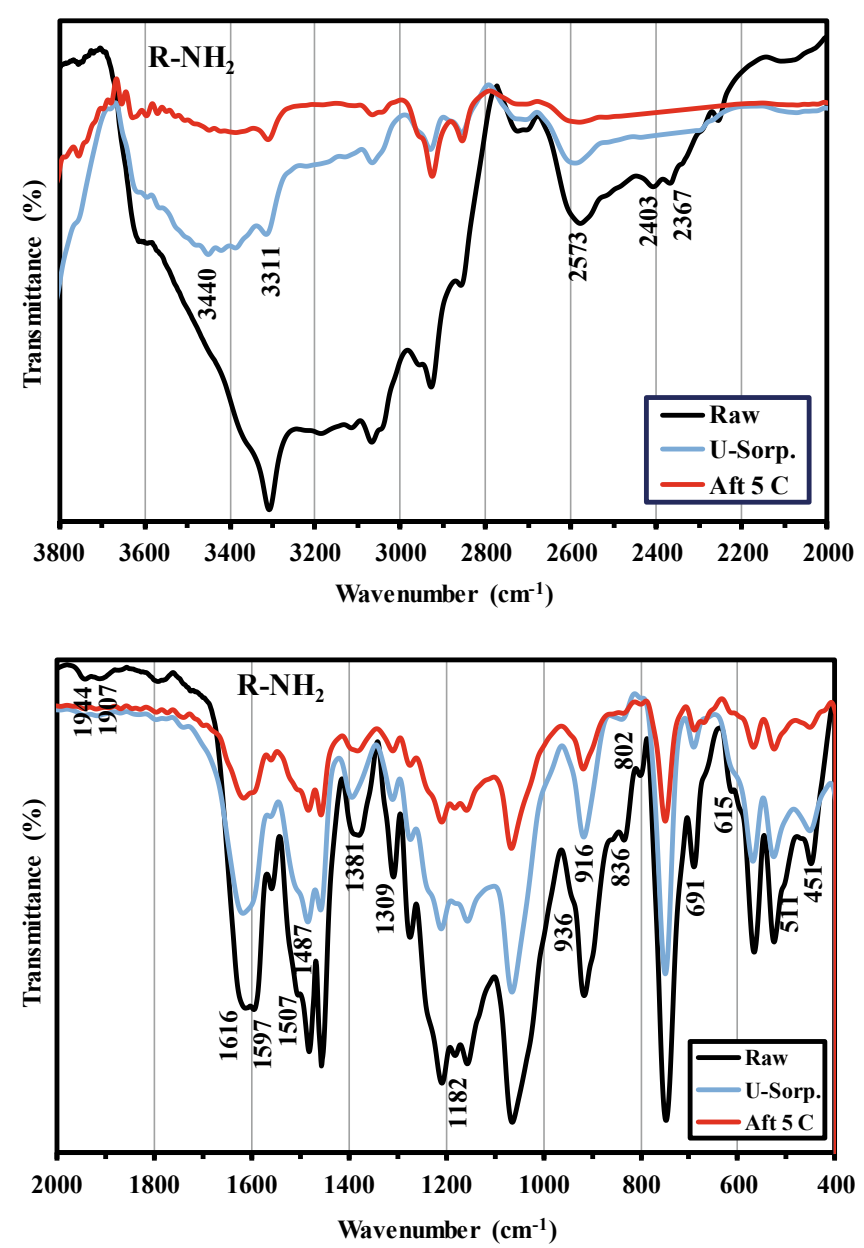

Fig. 2c. FTIR spectra of $\mathrm{R}-\mathrm{NH}_{2}$ before (raw) and after U(VI) sorption (U-Sorp.) and after 5 cycles of sorption and desorption (Aft.5C).

(shift of the peak at $3223 \mathrm{~cm}^{-1},-\mathrm{OH}$ bands), $1000-900 \mathrm{~cm}^{-1}$ (P-C bonds) and $600-400 \mathrm{~cm}^{-1}$. In the case of $\mathrm{R}^{-\mathrm{NH}_{2}}$ sorbent, the most significant changes for regenerated sorbent $v$ s. raw material are identified for $\mathrm{C}-\mathrm{H}$ groups (increased intensity at $2853 \mathrm{~cm}^{-1}$ and $2923 \mathrm{~cm}^{-1}$ ), in the range $1665-1560 \mathrm{~cm}^{-1}$ (width, and relative intensities of the peaks at $1614 \mathrm{~cm}^{-1}$ and $1597 \mathrm{~cm}^{-1}$ for amino groups). These variations clearly demonstrate that the sorbent is modified during the alternated cycles of sorption and desorption; this may explain the progressive (slight) decrease in sorption and desorption performances (see below, Section 3.2.4.). The decrease in sorption efficiency may be explained by the chemical change in the sorbent and the accumulation of uranyl (although uranyl band at $\approx 900 \mathrm{~cm}^{-1}$ does not appear clearly on the series of FTIR spectra).

\subsection{3. ${ }^{1} H$ NMR and ${ }^{31} P$ NMR spectroscopies}

The aromatic protons of the four benzene rings of $\alpha$-aminophosphonates (Fig. AM2a) show a complex multiplet at $\delta=6.50-7.27$ ppm for R-H, 7.14-7.83 ppm for R-COOH and 6.76-8.06 ppm for R- $\mathrm{NH}_{2}$. In addition, the carboxylate proton for $\mathrm{R}-\mathrm{COOH}$ appears at $\delta=12.98$ ppm and the NH proton exhibits a multiple singlet at $9.19 \mathrm{ppm}$. While the $\mathrm{P}-\mathrm{C}-\mathrm{H}$ proton signal appears as doublet at $\delta=5.25 \mathrm{ppm}(\mathrm{dd}, 1 \mathrm{H}, \mathrm{J}=$ $2.5 \& 3.0 \mathrm{~Hz}$ ) for R-H, $5.79 \mathrm{ppm}$ (dd, $1 \mathrm{H}, J=9 \mathrm{~Hz}$ ) for R-COOH and 4.90 ppm (d, $1 \mathrm{H}, J=24.5 \mathrm{~Hz}$ ), due to its coupling with phosphorus and proton of $\mathrm{N}-\mathrm{H}$. The $\mathrm{N}-\mathrm{H}$ proton signal appears at $\delta=5.42 \mathrm{ppm}$ as broad singlet and the $\mathrm{NH}_{2}$ proton show a singlet at $4.22 \mathrm{ppm}$ for $\mathrm{R}-\mathrm{NH}_{2}$. It worth to note that the $\mathrm{NH}$ proton signal of $\mathrm{R}-\mathrm{H}$ is not visible, may be due to either its overlapping with aromatic protons or exchange with deuterium from DMSO- $d_{6}$.
In the ${ }^{31} \mathrm{P}$ NMR spectra (Fig. AM2b), the appearance of a singlet for $\mathrm{R}-\mathrm{COOH}, \mathrm{R}-\mathrm{NH}_{2}$, and $\mathrm{R}-\mathrm{H}$, at $\delta=16.00,17.27$ and $17.72 \mathrm{ppm}$, respectively, confirms the formation of $\alpha$-aminophosphonate moiety. These assignments are consistent with values reported by Van der Veken et al. [40]. The side peaks appearing around ${ }^{31} \mathrm{P}$ NMR peaks are due to the presence of impurities or insufficiently washed reagents (notably for R-H and $\mathrm{R}-\mathrm{COOH}$ sorbents) and/or the presence of a chiral center (more specifically in the case of $\mathrm{R}-\mathrm{NH}_{2}$ sorbent).

\subsubsection{Thermal properties}

The thermogravimetric analysis of the sorbents, under $\mathrm{N}_{2}$ atmosphere, is reported on Fig. AM3. The degradation profiles of R-H and R$\mathrm{NH}_{2}$ sorbents are very similar; they are roughly constituted of three steps occurring in the same range of temperature and representing approximately the same weight losses. The first step represents the release of water absorbed at the surface of the sorbents; this step, occurring below $120-160{ }^{\circ} \mathrm{C}$, corresponds to a weight loss of about $4-5 \%$. The second step in the thermal degradation process appears as a first wave and takes place between $120{ }^{\circ} \mathrm{C}$ and $160{ }^{\circ} \mathrm{C}$ and about $491-511{ }^{\circ} \mathrm{C}$; weight loss reaches about $63 \%$ for $\mathrm{R}-\mathrm{H}$ and $59 \%$ for $\mathrm{R}-\mathrm{NH}_{2}$ (total weight loss $68 \%$ and $64 \%$, respectively). This is associated to the degradation of terminal reactive groups (essentially phosphonic groups). Liu et al. [41] commented that the bonds in $\mathrm{O}=\mathrm{P}-\mathrm{O}$ are less stable than the $\mathrm{C}-\mathrm{C}$ bond. This makes the phosphonic moiety more sensitive to thermal degradation than the remaining part of the sorbent. Actually in this degradation step, several poorly-resolved wavelets can be observed corresponding to the degradation of different reactive groups on the backbone of the polymer: specific changes in the slope of the degradation profile are observed at temperatures around $172{ }^{\circ} \mathrm{C}, 248^{\circ} \mathrm{C}, 380^{\circ} \mathrm{C}$ and $428^{\circ} \mathrm{C}$ for R-H. For R$\mathrm{NH}_{2}$, these changes are observed at $241^{\circ} \mathrm{C}, 299^{\circ} \mathrm{C}, 328^{\circ} \mathrm{C}, 370^{\circ} \mathrm{C}$ and $480{ }^{\circ} \mathrm{C}$. The last part in the process (above $440-460{ }^{\circ} \mathrm{C}$ ) represents the pyrolysis of the char [35]: the weight loss at $725^{\circ} \mathrm{C}$ reaches $71.0 \%$ for R$\mathrm{H}$ and $67.7 \%$ for $\mathrm{R}^{-\mathrm{NH}_{2}}$.

R-COOH sorbent exhibits a significantly different trend in terms of degradation profile. The first step, below $135^{\circ} \mathrm{C}$, corresponds to water release (about $4 \%$ weight loss, with a maximum at around $115{ }^{\circ} \mathrm{C}$ ). In the range $135-260{ }^{\circ} \mathrm{C}$, the weight loss is close to $31 \%$ (total $35 \%$, with a transition centered on $182{ }^{\circ} \mathrm{C}$ ). The third step (up to $515{ }^{\circ} \mathrm{C}$ ) shows a limited weight loss (16\%, total weight loss close to $51 \%)$ : the steeper slope in the degradation profile in this step is centered around $480^{\circ} \mathrm{C}$. Finally, the char degradation above $515^{\circ} \mathrm{C}$ shows a progressive weight loss; at $725{ }^{\circ} \mathrm{C}$, the total weight loss is close to $55.6 \%$.

While the presence of amine groups does not change the degradation profile compared with the reference (non-substituted) material, the carboxylic groups substantially change the stability of the material. The first degradation front is observed at a lower temperature; although the weight loss is decreased. On the opposite hand, the second degradation front occurs approximately in the same temperature range but the weight loss is also slightly reduced. The carboxylate groups induces a lower temperature for the beginning of the degradation but contributes to stabilize the sorbent at higher temperatures: final weight loss does not exceed $55 \%$ at $725{ }^{\circ} \mathrm{C}$ while for the other sorbents (i.e., $\mathrm{R}-\mathrm{H}$ and $\mathrm{R}-\mathrm{NH}_{2}$ ) the weight loss increases up to $68-71 \%$.

\subsubsection{Differential light scattering (DLS) and zetametry}

Fig. AM4 reports the DLS analysis of the three sorbents: the three materials have significantly different size profiles. $\mathrm{R}-\mathrm{H}$ has a bi-modal distribution profile: a small amount of particles is centered around $350 \mathrm{~nm}$, while the largest part of particles is centered above $531 \mathrm{~nm}$; the average particle size is set at $577 \mathrm{~nm}$. Other sorbents have narrower distribution of particle sizes (limited tail): $\mathrm{R}-\mathrm{COOH}$ has an average particle size close to the value reported for R-H; at $614 \mathrm{~nm}$. R-NH $\mathrm{N}_{2}$ is characterized by much lower particle sizes: the average size is close to $162 \mathrm{~nm}$.

The zeta potential values at $\mathrm{pH} 4$ are systematically negative and of the same order of magnitude for the three sorbents: $-21.5 \pm 4.72 \mathrm{mV}$ for 
$\mathrm{R}-\mathrm{H},-28.9 \pm 4.12 \mathrm{mV}$ for R-COOH and $-17.9 \pm 3.79 \mathrm{mV}$ for $\mathrm{R}^{-\mathrm{NH}_{2}}$. The more negative zeta potential of R-COOH compared with R-H (-21.5 $\pm 4.72 \mathrm{mV}$ ) can be explained by the presence of free carboxylic group that changes the surface properties of the sorbent: the -I withdrawing inductive effect of amino groups increases the density on the N-atom. On the opposite hand, in the case of $\mathrm{R}^{-\mathrm{NH}_{2}}$, the lower negative zeta potential is caused by free amine group that has $+\mathrm{I}$ donating inductive effect of amino groups, which, in turn, increases the density on the $\mathrm{N}$ atom. Obviously, the overall negative charge of the sorbent at $\mathrm{pH} 4$ may attract cationic uranyl species.

\subsubsection{Textural properties}

Fig. AM5 summarizes the textural properties of synthesized resins: specific surface area $\left(\mathrm{S}_{\mathrm{BET}}\right)$ (Fig. AM5a) and pore size distribution (Fig. AM5b). The $\mathrm{S}_{\mathrm{BET}}$ of $\mathrm{R}-\mathrm{H}$ resin is close to $9.1 \mathrm{~m}^{2} \mathrm{~g}^{-1}$; the substitution of carboxylic groups and amine groups during the synthesis of sorbents leads to a significant decrease of the $\mathrm{S}_{\mathrm{BET}}$ to $2.8 \mathrm{~m}^{2} \mathrm{~g}^{-1}$ for $\mathrm{R}-\mathrm{NH}_{2}$ and even less (i.e., $1.5 \mathrm{~m}^{2} \mathrm{~g}^{-1}$ ) for R-COOH. The $-\mathrm{NH}_{2}$ and $-\mathrm{COOH}$ groups contribute to increase the steric hindrance and limit the specific surface area of final material. It is noteworthy that the nitrogen adsorption/ desorption isotherms can be characterized by a "Type II" shape according Langmuir classification: the hysteresis loop is hardly detectable while comparing sorption and desorption curves. This type of isotherm is frequently associated with a wide distribution of pore sizes. Table AM3 shows that the pore volume decreases with $-\mathrm{NH}_{2}$ and $\mathrm{COOH}$ functionalization; this is consistent with the discussion of specific surface area. Fig. AM5b shows the distribution of pore size for the three resins. The functional groups (i.e., $-\mathrm{NH}_{2}$ and $-\mathrm{COOH}$ ) significantly change the profile of pore distribution: the pore size is substantially decreased, especially for R-COOH (most of pores being lower in size than $10 \mathrm{~nm}$ ). In the case of $\mathrm{R}^{-\mathrm{NH}_{2}}$, a first sharp peak of size is observed at 8 $\mathrm{nm}$ followed by a flat peak at $36 \mathrm{~nm}$. These two sorbents can be roughly considered microporous. In the case of the R-H sorbent, a branch of pores (poorly resolved) is also observed at $36 \mathrm{~nm}$ completed by a very flat and large pore distribution peak (centered around $106 \mathrm{~nm}$ ). Contrary to $-\mathrm{NH}_{2}$ and $-\mathrm{COOH}$ functionalized sorbents, $\mathrm{R}-\mathrm{H}$ material can be qualified as a mesoporous sorbent.

\subsection{7. $p H_{P Z C}$}

The $\mathrm{pH}$-drift method is used for the determination of the $\mathrm{pH}_{\mathrm{PZC}}$ and the characterization of the acid-base properties of $\alpha$-aminophosphonatebased sorbents $\left(\mathrm{R}-\mathrm{H}, \mathrm{R}-\mathrm{COOH}\right.$, and $\left.\mathrm{R}-\mathrm{NH}_{2}\right)[3,25]$. The $\mathrm{pH}_{\mathrm{PZC}}$ values of the different sorbents were close to $4.75,4.01$ and 5.71 for R-H, R$\mathrm{COOH}$, and $\mathrm{R}-\mathrm{NH}_{2}$ sorbents, respectively (Fig. AM6). The expected chemical structures of the $\alpha$-aminophosphonate derivatives (Scheme 2) allow explaining these differences. The sorbent R-H (produced using aniline, the "simplest" aromatic amine) can be considered the reference material. While using anthranilic acid (o-aminobenzoic acid), the $\mathrm{pH}_{\mathrm{PZC}}$ decreases from 4.75 to 4.01 , due to the insertion of carboxylic acid moiety with $\mathrm{pK}_{\mathrm{a}}$ around 4 (or lower) [36,42]. In the case of o-phenylene diamine (o-aromatic diamine), the insertion of amine groups brings additional basic sites that lead to a shift of the $\mathrm{pH}_{\mathrm{PZC}}$ from 4.75 to 5.71 ; amine groups have high $\mathrm{pK}_{\mathrm{a}}$ values (9.21 for amino groups of ammonia and primary amines [43]). This scaling in the values of $\mathrm{pH}_{\mathrm{PZC}}$ for the three derivatives is consistent with the ranking of their zeta potentials at $\mathrm{pH} 4$ (see above). These changes in the $\mathrm{pH}_{\mathrm{PZC}}$ confirm the effectiveness of the synthesis of different aminophosphonate compounds whose properties are modulated by the inserted secondary reactive groups (i.e., amines or carboxylic groups).

It is noteworthy that the values of $\mathrm{pH}_{\mathrm{PZC}}$ are not consistent with the zetametry measurements that showed negative charges for the three sorbents at $\mathrm{pH} 4$. However, the two sets of characterization respect the ranking of charge $/ \mathrm{pH}_{\mathrm{PZC}}$.

\subsection{Sorption properties}

\subsubsection{Effect of $p H$}

Designing metal sorption process requires optimizing the $\mathrm{pH}$ of sorption and more generally understanding the effect of this parameter on (a) the speciation of the metal (in function of the presence of ligands), and (b) the surface charge of the sorbent (protonation/deprotonation of reactive groups). Fig. 3 compares the effect of $\mathrm{pH}_{\mathrm{eq}}$ on $\mathrm{U}(\mathrm{VI})$ sorption capacity for $\mathrm{R}-\mathrm{H}, \mathrm{R}-\mathrm{COOH}$ and $\mathrm{R}-\mathrm{NH}_{2}$, in the range $1-6$. Above $\mathrm{pH} 5$, the formation of hydrocolloids species causes a partial precipitation of uranyl under the form of hydrolyzed species (i.e., $\mathrm{UO}_{2}(\mathrm{OH})_{2} \cdot \mathrm{H}_{2} \mathrm{O}$ ). The three curves almost overlap up to $\mathrm{pH} 3$ : under selected experimental conditions, sorption capacity slightly increases from $0.045 \mathrm{mmol} \mathrm{U} \mathrm{g}^{-1}$ to $0.14-0.16 \mathrm{mmol} \mathrm{U} \mathrm{g}^{-1}$. Above $\mathrm{pH} \mathrm{3}$, sorption capacity significantly increases to reach a maximum that depends on the substitution of the sorbent. Indeed, for $\mathrm{R}-\mathrm{H}$, the maximum is reached at $\mathrm{pH}_{\mathrm{eq}} 3.76$ and the sorption capacity approaches $0.312 \mathrm{mmol} \mathrm{U} \mathrm{g}^{-1}$. For R-COOH, the maximum sorption decreases to $0.249 \mathrm{mmol} \mathrm{U} \mathrm{g}^{-1}$ at pH 3.4, while for $\mathrm{R}-\mathrm{NH}_{2}$, the maximum sorption capacity (up to $0.377 \mathrm{mmol} \mathrm{U} \mathrm{g}^{-1}$ ) is achieved at higher $\mathrm{pH}$ (i.e., $\mathrm{pH}_{\mathrm{eq}}$ : 4.38). After reaching the optimum $\mathrm{pH}_{\mathrm{eq}}$ value, the sorption capacity strictly decreases with $\mathrm{pH}$ augmentation. It is noteworthy that the shift in the optimum equilibrium $\mathrm{pH}$ value $\left(\mathrm{pH}_{\text {opt. }}\right)$ is directly correlated to the $\mathrm{pH}_{\mathrm{PZC}}$ values: $\mathrm{pH}_{\mathrm{opt}}=1.05+0.58$ $\mathrm{pH}_{\mathrm{PZC}}\left(\mathrm{R}^{2}:\right.$ 0.994). The sorption capacity at optimum $\mathrm{pH}\left(\mathrm{q}_{\text {opt.pH }}\right)$ value is also correlated to the $\mathrm{pH}_{\mathrm{PZC}}$ according: $\mathrm{q}_{\mathrm{opt}} \mathrm{pH}=0.128 \mathrm{pH}_{\mathrm{PZC}}-0.179$. The superposition of the curves for the three sorbents, and the variations, at the higher $\mathrm{pH}$ values, that are controlled by $\mathrm{pH}_{\mathrm{PZC}}$, mean that this is precisely the modulating acidity/basicity of the substitute that is controlling the sorption efficiency of the sorbent. The optimum $\mathrm{pHs}$ for the three sorbents correspond to the same initial $\mathrm{pH}$ value (i.e., $\mathrm{pH}_{0}: 4$ ). This is the $\mathrm{pH}$ value selected for further experiments.

Actually, the ranking in optimum sorption capacities ( $\mathrm{q}_{\mathrm{opt} . \mathrm{pH}}$ ) can be also explained by the increase in the density of sorption groups in the case of $\mathrm{R}-\mathrm{NH}_{2}$ : the grafting of phenylene diamine allows increasing amine groups at the surface of the sorbent (Table 1) and then the capacity of the sorbent to bind more uranyl ions. The solution $\mathrm{pH}$ plays a key role in the sorption process since it affects the chemistry of both the sorbent and the sorbate (here U(VI) ions). On the opposite hand, in the case of $\mathrm{R}-\mathrm{COOH}$, the sorption capacity decreases due to several factors including steric hindrance, reported changes in the acid-base properties but also criteria such as affinity for target metal according the Hard and Soft Acid Base rules [13]. Indeed, uranyl is part of hard acids, which have higher affinity and reactivity for hard bases such as amine groups

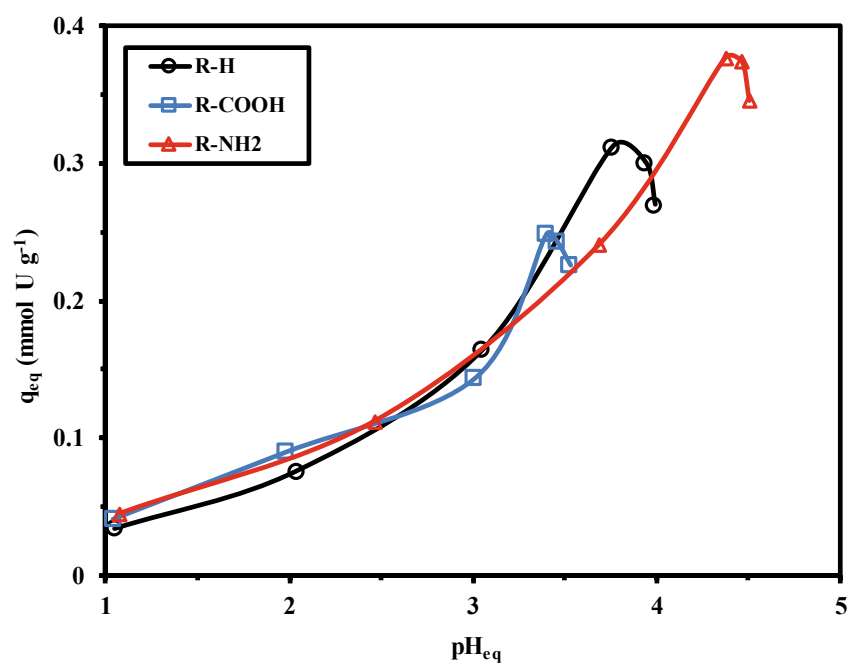

Fig. 3. Effect of $\mathrm{pH}$ on $\mathrm{U}(\mathrm{VI})$ sorption: sorption capacity versus initial $\mathrm{pH}$. $\left(\mathrm{C}_{0}\right.$ : $0.210 \mathrm{mmol} \mathrm{U} \mathrm{L}{ }^{-1}$; $\mathrm{T}: 25^{\circ} \mathrm{C}$; SD: $0.5 \mathrm{~g} \mathrm{~L}^{-1}$; Time: $210 \mathrm{~min}$; agitation speed: $200 \mathrm{rpm})$. 
(more than with carboxylic groups). The wide diversity of reactive groups held on the three sorbents may explain the overall affinity of these materials for uranyl species, through interactions with chelating agents bearing $\mathrm{O}, \mathrm{N}$, and $\mathrm{P}$ groups $[3-5,10,12,16]$. On the other hand, the lower sorption efficiency of R-COOH sorbent than $\mathrm{R}^{-\mathrm{NH}_{2}}$ and $\mathrm{R}-\mathrm{H}$, may be explained by steric hindrance effects of the carboxylate group at the ortho-position (this may also affect the acid-base properties sorbent). The type of substituent controls the improvement or loss in sorption affinity (and sensitivity to $\mathrm{pH}$ ). Chandrasekar et al. [39] investigated the extraction of uranyl nitrate (and actinides) using H-phosphonate-based extractants and demonstrate that the sorption mechanisms changes with the acidity: at weak acidity, uranyl was bound by ion-exchange through tautomerization effect on $\mathrm{O}=\mathrm{P}$ - group of phosphonate while at higher acidity $\left(>1 \mathrm{M} \mathrm{HNO}_{3}\right.$ ) solvation was involved in metal extraction. They highlighted the importance of weak-hydrogen bonding on the chemistry of uranyl coordination (though stabilization effects). This may contribute to modulate the sorption properties of the different substituents.

The distribution ratio ( $\mathrm{D}: \mathrm{q}_{\mathrm{eq}} / \mathrm{C}_{\mathrm{eq}}, \mathrm{L} \mathrm{g}^{-1}$ ) is plotted against the equilibrium $\mathrm{pH}$ (Fig. AM7). The $\log _{10}$ plot $v s . \mathrm{pH}_{\mathrm{eq}}$ is linear (before the beginning of uranyl precipitation; i.e., for $\mathrm{pH}_{\mathrm{eq}}$ data ranging between 1 and 5). The slope of these linear curves ranges between 0.445 and 0.571 . This means that uranyl binding may involve a stoichiometric proton exchange close to two protons/uranyl ion. This stoichiometric ratio can be related to the speciation diagram of uranyl in sulfate/sulfuric acid solutions (Fig. AM8). At pH 1, the neutral uranyl sulfate species (i.e., $\mathrm{UO}_{2} \mathrm{SO}_{4}$ ) predominates $(65 \%)$ with the presence of free uranyl (about $21 \%)$ and anionic species $\left(\mathrm{UO}_{2}\left(\mathrm{SO}_{4}\right)_{2}^{2-}\right.$, for $\left.14 \%\right)$. When the $\mathrm{pH}$ increases up to 4 , the fraction of uranyl progressively increases to reach about $73 \%$, while anionic species disappear and uranyl sulfate decreases to $17 \%$, some hydrolyzed species positively charged also appear (such as $\mathrm{UO}^{2}(\mathrm{OH})^{+},\left(\mathrm{UO}_{2}\right)_{2}(\mathrm{OH})_{2}^{2+}$, and $\left.\left(\mathrm{UO}_{2}\right)_{3}(\mathrm{OH})_{5}^{+}\right)$. This progressive increase of divalent uranyl species is correlated to the increase in free uranyl concentration: Fig. AM9 superimposes the $\mathrm{pH}$-sorption capacity curves with the distribution of uranyl species. Between $\mathrm{pH} 4$ and $\mathrm{pH} 5$ the fraction of free uranyl species strongly decreases, while hydrolyzed polynuclear species begin to appear: U(VI) sorption sharply decreases. Above $\mathrm{pH}$, hydrolyzed polynuclear species predominate and uranyl begins to precipitate.

Fig. AM10 shows the $\mathrm{pH}$ variation after uranyl sorption. In the range $\mathrm{pH} 1-3$, the equilibrium $\mathrm{pH}$ is not changed for $\mathrm{R}-\mathrm{H}$ and $\mathrm{R}-\mathrm{COOH}$ sorbents: this is due to the neutral (R-H) or acid (R-COOH) behavior of the specific moiety inserted on the polymer. At $\mathrm{pH} 4$, the $\mathrm{pH}$ is hardly affected for R-H (this may be correlated to its $\mathrm{pH}_{\mathrm{PZC}}$ value, close to 4), while for $\mathrm{R}-\mathrm{COOH}$ the $\mathrm{pH}$ tends to decrease by $0.6 \mathrm{pH}$ unit). The case of $\mathrm{R}-\mathrm{NH}_{2}$ (bearing weakly basic moiety) is substantially different: the equilibrium $\mathrm{pH}$ increases with sorption by $0.4-0.7 \mathrm{pH}$ unit in the range $\mathrm{pH} 2-4$. The basic function binds protons, consistently with the $\mathrm{pH}_{\mathrm{PZC}}$ of the sorbent. Above $\mathrm{pH}_{0} 4$, the equilibrium $\mathrm{pH}$ tends to decrease; this is probably associated to the release of protons involved in uranyl binding. It is noteworthy that in the range $\mathrm{pH} 4-6$, the equilibrium $\mathrm{pH}$ tends to stabilize around $\mathrm{pH}_{\text {stab. }}: 3.5$ for R-COOH, 4.0 for R-H and 4.5 for $\mathrm{R}-\mathrm{NH}_{2}$. This "buffering effect" is coherent with the acid-base properties of the sorbents: $\mathrm{pH}_{\text {stab. }}=1.179+0.585 \mathrm{pH}_{\mathrm{PZC}}\left(\mathrm{R}^{2}: 0.994\right)$.

\subsubsection{Uptake kinetics}

The uptake kinetics are reported in Fig. 4. The three sorbents show similar kinetic profiles: the initial section (first 15-20 min of contact) is roughly superimposed for the different curves and the equilibrium is reached within $60-180 \mathrm{~min}$. The initial section of the curve is usually associated with a mass transfer controlled by the resistance to film diffusion: the superimposition of the curves means that the sorbents are similar in terms of external diffusion. The equilibrium is reached a little faster (within $60 \mathrm{~min}$ ) for R-COOH sorbent, while $\mathrm{R}-\mathrm{H}$ and $\mathrm{R}-\mathrm{NH}_{2}$ require 120 and $180 \mathrm{~min}$, respectively (though $>95 \%$ of total sorption is reached within $60 \mathrm{~min}$ for both $\mathrm{R}-\mathrm{H}$ and $\mathrm{RNH}_{2}$ ). Resistance to
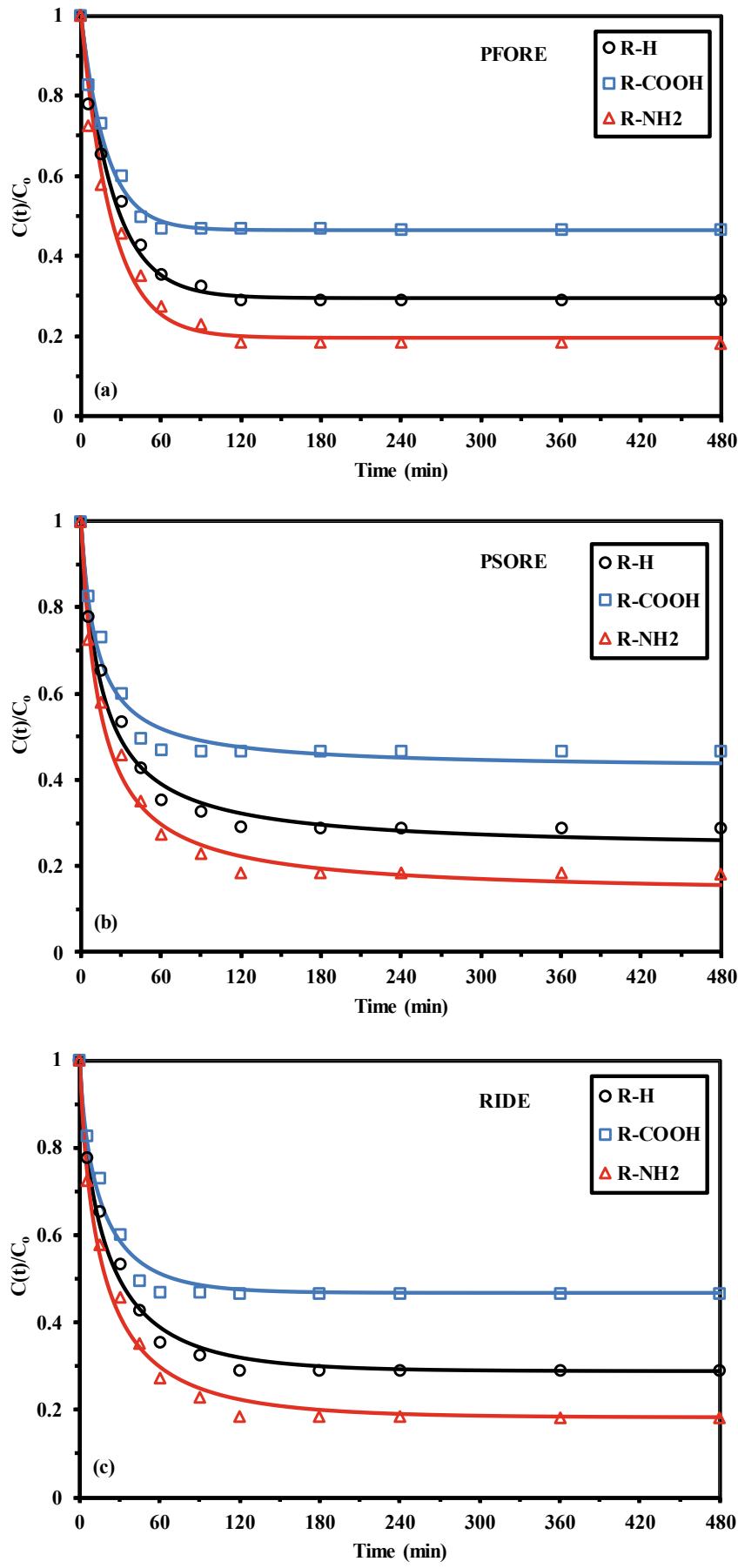

Fig. 4. Uptake kinetics for $\mathrm{U}(\mathrm{VI})$ sorption using $\mathrm{R}-\mathrm{H}$, R-COOH, and $\mathrm{R}-\mathrm{NH}_{2}$ sorbents - Modeling with PFORE, PSORE and RIDE $\left(\mathrm{pH}_{0}: 4.02 ; \mathrm{C}_{0}: 0.325 \mathrm{mmol}\right.$ $\mathrm{U} \mathrm{L}^{-1}$; $\mathrm{T}$ : $25^{\circ} \mathrm{C}$; SD: $0.5 \mathrm{~g} \mathrm{~L}^{-1}$; agitation speed: $\left.200 \mathrm{rpm}\right)$.

intraparticle diffusion (RIDE, modelled by the Crank equation) may control uptake kinetics, in addition to resistance to film diffusion, but also by the proper reaction rate (under the control of hydration, $\mathrm{pH}$ effect on charge neutralization), modelled using the pseudo-first order rate equation (PFORE) and the pseudo-second order rate equation (PSORE) (Table AM1). Fig. 4 compares the fits of experimental profiles for the three sorbents with the three models. Table 2 reports the parameters of these models (including the determination coefficients, $\mathrm{R}^{2}$ ); the appropriateness of the model (PFORE vs. PSORE) is also measured comparing the experimental value of the equilibrium sorption capacities $\left(\mathrm{q}_{\mathrm{eq}, \exp }\right)$ with the calculated values $\left(\mathrm{q}_{\mathrm{eq}, 1}\right.$ or $\left.\mathrm{q}_{\mathrm{eq}, 2}\right)$. The determination 
Table 2

Uptake kinetics for U(VI) sorption using R-H, R-COOH and R- $\mathrm{NH}_{2}$ sorbents - Model parameters for the PFORE, the PSORE and the RIDE.

\begin{tabular}{|c|c|c|c|c|c|}
\hline \multirow[t]{2}{*}{ Sorbent } & \multirow[t]{2}{*}{$\mathrm{q}_{\mathrm{eq}, \exp }\left(\mathrm{mmol} \mathrm{U} \mathrm{g}{ }^{-1}\right)$} & \multicolumn{4}{|l|}{ PFORE } \\
\hline & & $\mathrm{q}_{\mathrm{eq}, 1}\left(\mathrm{mmol} \mathrm{U} \mathrm{g}^{-1}\right)$ & $\mathrm{k}_{1} \times 10^{2}\left(\mathrm{~min}^{-1}\right)$ & $\mathrm{R}^{2}$ & AIC \\
\hline R-H & 0.462 & 0.458 & 4.18 & 0.986 & -79 \\
\hline $\mathrm{R}-\mathrm{COOH}$ & 0.346 & 0.348 & 5.25 & 0.989 & -90 \\
\hline \multirow[t]{3}{*}{ R-NH ${ }_{2}$} & 0.531 & 0.523 & 4.37 & 0.980 & -71 \\
\hline & & PSORE & & & \\
\hline & & $\mathrm{q}_{\mathrm{eq}, 1}\left(\mathrm{mmol} \mathrm{U} \mathrm{g}{ }^{-1}\right)$ & $\mathrm{k}_{2} \times 10^{2}\left(\mathrm{~g} \mathrm{mmol}^{-1} \min ^{-1}\right)$ & $\mathrm{R}^{2}$ & AIC \\
\hline R-H & 0.462 & 0.495 & 13.3 & 0.987 & -82 \\
\hline $\mathrm{R}-\mathrm{COOH}$ & 0.346 & 0.373 & 22.8 & 0.971 & -80 \\
\hline \multirow[t]{3}{*}{$\mathrm{R}-\mathrm{NH}_{2}$} & 0.531 & 0.564 & 12.5 & 0.989 & -81 \\
\hline & & RIDE & & & \\
\hline & & $D_{\text {eff }} \times 10^{10}\left(\mathrm{~m}^{2} \min ^{-1}\right)$ & & $\mathrm{R}^{2}$ & AIC \\
\hline R-H & & 3.16 & & 0.992 & -88 \\
\hline $\mathrm{R}-\mathrm{COOH}$ & & 6.73 & & 0.983 & -85 \\
\hline R-NH ${ }_{2}$ & & 0.181 & & 0.983 & -85 \\
\hline
\end{tabular}

coefficients are of the same order of magnitude for the different systems and it is difficult finding a clear preference in the modeling of kinetic profiles on this unique criterion. The comparison of the equilibrium sorption capacities shows that the PFORE allows approaching closer to the experimental value than the PSORE: the $\Delta \mathrm{q}_{\mathrm{eq}}$ ranges between $-1.5 \%$ and $+1 \%$ for PFORE while the PSORE overestimates $\mathrm{q}_{\text {eq }}$ by $6-8 \%$. The sorbents are synthesized as objects of irregular shape and the particle size was characterized by DLS. For the modeling of the resistance to intraparticle diffusion, the Crank equation was used, considering, as a first approximation, that the particles are roughly spherical. The RIDE fails to fit the time range corresponding to the highest curvature in the uptake profile (around 45-90 min). The effective diffusivity ( $D_{\text {eff }}$ ) ranges

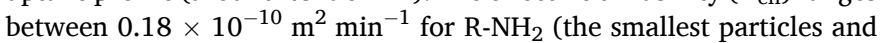
slowest kinetics), $3.2 \times 10^{-10} \mathrm{~m}^{2} \mathrm{~min}^{-1}$ for R-H and $6.7 \times 10^{-10} \mathrm{~m}^{2}$ $\mathrm{min}^{-1}$ for $\mathrm{R}-\mathrm{COOH}$. These values are about 2 orders of magnitude lower than the free diffusivity of uranyl in water (i.e., $\mathrm{D}_{0}: 2.56 \times 10^{-8} \mathrm{~m}^{2}$ $\mathrm{min}^{-1}$, [44]). This means that the resistance to intraparticle diffusion plays a non-negligible effect on the control of mass transfer [45]. Despite the smallest size of $\mathrm{R}^{-\mathrm{NH}_{2}}$ sorbent (Fig. AM4), uranyl uptake is slower than for the other sorbents; this is confirmed by the lowest value of effective diffusivity. Surprisingly, despite significant decrease in pore size for $\mathrm{R}-\mathrm{NH}_{2}$ and R-COOH (compared with R-H), these materials do not show slowdown in overall kinetics. This is another evidence that the resistance to intraparticle diffusion is not the critical step in the mass transfer.

As expected (after the study of pH effect), the sorption capacities at equilibrium follow the series: $\mathrm{R}-\mathrm{NH}_{2}>\mathrm{R}-\mathrm{H}>\mathrm{R}-\mathrm{COOH}$. The comparison of the apparent rate coefficients (Table 2) shows that both $\mathrm{k}_{1}$ and $\mathrm{k}_{2}$ are of the same order of magnitude for $\mathrm{R}-\mathrm{H}$ and $\mathrm{R}-\mathrm{NH}_{2}$, while the relevant values are little higher for R-COOH. The substituent not only influences the affinity of the sorbent for uranyl (for controlling equilibrium distribution of metal ions) but also affects the transfer kinetics.

The pseudo-second order rate equation is usually associated with chelation mechanism while the pseudo-first order rate equation is used for modeling physical sorption mechanism. Though a little preference may be given to the PFORE for fitting kinetic profiles, both of them give good fit of experimental profiles and it is thus difficult discriminating between the physical and the chemical interpretation of $\mathrm{U}(\mathrm{VI})$ uptake mechanism on the basis of the kinetic study.

\subsubsection{Sorption isotherms and thermodynamic parameters}

Sorption isotherms have been investigated at three temperatures $\left(25^{\circ} \mathrm{C}, 35^{\circ} \mathrm{C}\right.$ and $45^{\circ} \mathrm{C}$ ). Fig. 5 summarizes these data for R-H, RCOOH and $\mathrm{R}-\mathrm{NH}_{2}$. All these experimental profiles are characterized by a steep initial slope (residual concentration being lower than $0.05 \mathrm{mmol} \mathrm{U} \mathrm{L}^{-1}$ ) followed by a progressive increase of sorption capacity, before reaching a saturation plateau. The steepness of the initial slope follows the sequence: $\mathrm{R}-\mathrm{NH}_{2}>\mathrm{R}-\mathrm{COOH} \approx \mathrm{R}-\mathrm{H}$. The affinity of the sorbent for target sorbate is correlated to this initial slope of the sorption isotherm: this means that $\mathrm{R}-\mathrm{NH}_{2}$ has a stronger interaction with uranyl species at low metal concentration. On the other hand, the comparison of saturation capacities shows a different trend: $\mathrm{R}-\mathrm{H}>\mathrm{R}-\mathrm{NH}_{2}>\mathrm{R}-\mathrm{COOH}$. This ranking is also different from the order reported during the study of $\mathrm{pH}$ effect. At low $\mathrm{U}(\mathrm{VI})$ concentration (as used for the study of $\mathrm{pH}$ effect), the strong affinity of $\mathrm{R}^{-\mathrm{NH}_{2}}$ at low metal concentration (steeper initial slope of isotherm) reverses the order of preference observed at the saturation plateau.

The sorbents show substantial differences while considering the effect of the temperature. In the case of $\mathrm{R}-\mathrm{H}$ and $\mathrm{R}-\mathrm{NH}_{2}$, the sorption capacities slightly and continuously increase with the temperature from 1.057 to $1.1665 \mathrm{mmol} \mathrm{U} \mathrm{g}^{-1}$, and from 0.746 to $0.803 \mathrm{mmol} \mathrm{U} \mathrm{g}^{-1}$ : their sorption is endothermic. On the opposite hand, the sorption of uranyl on $\mathrm{R}-\mathrm{COOH}$ is exothermic: the sorption capacity decreases from 0.535 to $0.499 \mathrm{mmol} \mathrm{U} \mathrm{g}^{-1}$ with increasing the temperature.

The affinity (indicated by the initial slope) is more influenced by temperature for $\mathrm{R}-\mathrm{H}$ than for $\mathrm{R}-\mathrm{COOH}$ (and even more than for $\mathrm{R}-\mathrm{NH}_{2}$ ). Apparently, the ranking of sorbents, based on maximum sorption capacities is contradictory with the ranking in equilibrium sorption capacities reported in the section "uptake kinetics". Actually, the difference in the affinities of the sorbents (i.e., $b_{\mathrm{L}}$, proportional to the initial slope of the isotherm curve) for $\mathrm{U}(\mathrm{VI})$ induces some differences in the ranking with the concentration range. At low metal concentration (i. e., $50 \mathrm{mg} \mathrm{U} \mathrm{L}^{-1}$, the concentration used for uptake kinetics), the sorption capacity of $\mathrm{R}-\mathrm{NH}_{2}$ is higher than that of R-H.

Different effects may control the preference of uranyl ions for the different sorbents:

(a) The HSAB concept - Uranyl is considered a hard acid according Pearson's rules; this means that the metal ion bind preferentially to ligands bearing $\mathrm{N} \gg \mathrm{P}, \mathrm{O} \gg \mathrm{S}$.

(b) Carboxylic groups are protonated at $\mathrm{pH}$ below 4 , minimizing the electrostatic attraction effect.

(c) The electron-withdrawing/releasing effect affect the donating ability of phosphonate functional groups (negatively for carboxylic acid groups, positively for amine groups).

(d) The steric effect modulates the accessibility to reactive groups: bulky carboxylic groups cause stronger steric hindrance than for amine groups (and even more when comparing with R-H).

(e) The specific surface area is also controlling the reactive surface available for interaction with uranyl ions ( $\mathrm{R}-\mathrm{H}>\mathrm{R}-\mathrm{NH}_{2}>\mathrm{RCOOH}$ ).

The relative contribution of these different effects is difficult to establish. Hermann and Lukes [46] investigated the binding properties of a series of phosphonodipepetides bearing different functional groups for divalent cations. They reported the critical effects of deprotonation properties and the steric hindrance effect attached to the amino acid side chains. However, they also commented that the influence of these parameters is modulated by the strong complexing ability of the 

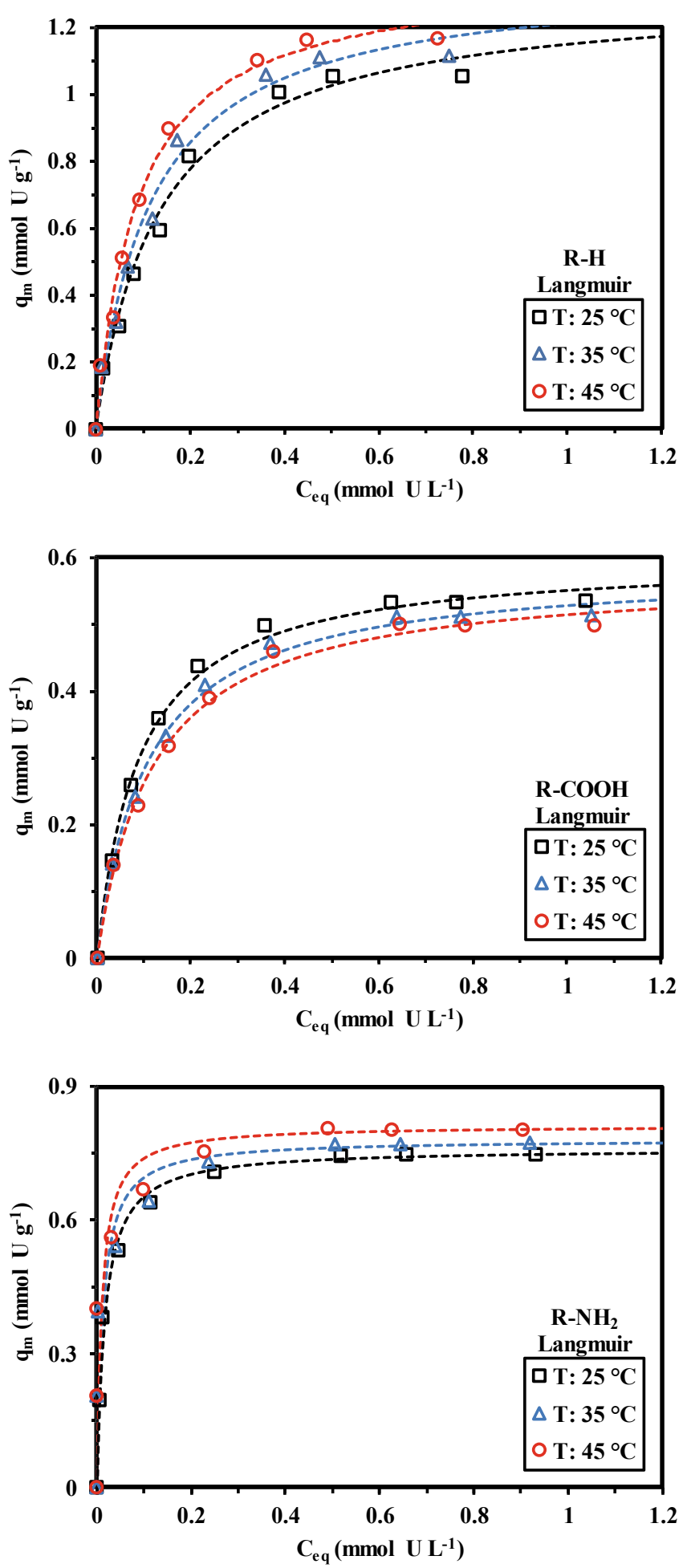

Fig. 5. U(VI) sorption isotherms using $\mathrm{R}-\mathrm{H}, \mathrm{R}-\mathrm{COOH}$, and $\mathrm{R}-\mathrm{NH}_{2}$ sorbents at different temperatures - Modeling with the Langmuir equation $\left(\mathrm{pH}_{0}: 4.07\right.$; time: $3 \mathrm{~h}$; T: 25,35 , and $45^{\circ} \mathrm{C}$; SD: $0.5 \mathrm{~g} \mathrm{~L}^{-1}$ ).

phosphonic groups (compared to the stronger effect observed with more conventional dipeptides).

The isotherms are fitted by the Langmuir equation (Fig. 5), the Sips equation (Fig. AM11) and the Temkin equation (Fig. AM12) (see Table AM1 for relevant equations). The Freundlich equation being a power-like function is not appropriate for fitting the asymptotic trend of isotherm profiles (the fits are not represented). Table 3 summarizes the parameters of the Langmuir, Freundlich and Sips equations while the parameters for the Temkin equation are reported in Table 4. The Sips equation is derivated from the Langmuir equation by introducing a Freundlich-like exponential term. Adding a supplementary parameter introduces greater flexibility in the mathematical fir of experimental profiles; here, the determination coefficients are weakly improved and the exponential additional term is close to 1 for $\mathrm{R}-\mathrm{H}$ and $\mathrm{R}-\mathrm{COOH}$ showing that the Sips equation is not appropriate for fitting isotherm data. In the case of $\mathrm{R}^{-\mathrm{NH}_{2}}$, the exponential term increases from 1.24 to 3.3 with increasing temperature. Therefore, the introduction of the exponential term affects more significantly the simulation of experimental profiles at higher temperatures. Globally, the best fits are obtained with the Langmuir equation. This model suggests that solute sorption occurs through monolayer coverage with homogeneous energy distribution and finite number of identical sites (homogeneous interaction of reactive groups with target metals) homogeneously distributed over the sorbent surface and without interactions between sorbed molecules $[10,47]$. The mathematical fit does not prove that the hypotheses of the model are fulfilled; this should be demonstrated by other physicochemical characterizations. The value of $\mathrm{R}_{\mathrm{L}}$, a dimensionless constant defined by $R_{L}=\left(1+b_{L} C_{o}\right)^{-1}$, is frequently used for evaluating the favorable character of the sorption process: when $R_{L}>1$, the sorption is favorable $[3,47,48]$. Here, for initial concentrations ranging between 0.105 and $1.3 \mathrm{mmol} \mathrm{U} \mathrm{g}^{-1}$ : the $\mathrm{R}_{\mathrm{L}}$ coefficients decrease with concentration from 0.57 to 0.095 for $\mathrm{R}-\mathrm{H}$, from 0.53 to 0.08 for $\mathrm{R}-\mathrm{COOH}$ and from 0.46 to 0.06 for $\mathrm{R}^{-\mathrm{NH}_{2}}$. The value of $\mathrm{R}_{\mathrm{L}}$ is strictly inferior to 1 : the sorption is favorable and the favorability increases with metal concentration.

The Temkin isotherm assumes that the free energy of sorption is a function of the surface coverage $[49,50]$. Table 4 summarizes the values of Temkin parameters. The constant $\mathrm{A}_{\mathrm{T}}$ reflects the initial sorption heat: the greater the $A_{T}$ value, the higher the sorption heat, and the greater the affinity of the sorbent for the sorbate. The $A_{T}$ values for R-H and R$\mathrm{COOH}$ have the same order of magnitude (in the range 100-165 L $\mathrm{mmol}^{-1}$ ); although their variation is different: for $\mathrm{R}-\mathrm{H}, \mathrm{A}_{\mathrm{T}}$ decreases with increasing the temperature contrary to R-COOH. The $A_{T}$ value is much higher for $\mathrm{R}^{-\mathrm{NH}_{2}}$ (increasing with temperature from 2714 to almost $2900 \mathrm{~L} \mathrm{mmol}^{-1}$ ). The much higher value of $\mathrm{A}_{\mathrm{T}}$ can be correlating with the very favorable sorption of uranium at low metal concentration for $\mathrm{R}^{-\mathrm{NH}_{2}}$ (quasi-irreversible profile at low metal concentration). The energetic parameter (i.e., $\mathrm{b}_{\mathrm{T}}$ ) increases according the sequence: $\mathrm{R}-\mathrm{H}$ $\left(9.7-10.2 \mathrm{~kJ} \mathrm{~mol}^{-1}\right)<\mathrm{R}-\mathrm{COOH}\left(21.3-22.9 \mathrm{~kJ} \mathrm{~mol}^{-1}\right)<\mathrm{R}^{-\mathrm{NH}_{2}}$ (larger variations between 24 and $32 \mathrm{~kJ} \mathrm{~mol}^{-1}$ ).

The thermodynamic parameters of sorption (including enthalpy change, $\Delta \mathrm{H}^{\circ}, \mathrm{kJ} \mathrm{mol}^{-1}$; entropy change, $\Delta \mathrm{S}^{\circ}, \mathrm{J} \mathrm{mol}^{-1} \mathrm{~K}^{-1}$; and Gibbs free energy change, $\Delta \mathrm{G}^{\circ}, \mathrm{kJ} \mathrm{mol}^{-1}$ ) are deduced from van't Hoff equation using the normalized affinity coefficient of the Langmuir equation (i.e., $\mathrm{b}_{\mathrm{L}}{ }^{*}$ ) for the different temperatures and different sorbents (Table 3 ) $[3,48,51]$ :

$\ln b_{L}^{*}=\frac{-\Delta H^{\circ}}{R \times T}+\frac{\Delta S^{\circ}}{R}$

$\Delta G^{\circ}=\Delta H^{\circ}-T \Delta S^{\circ}$

The normalization of $b_{\mathrm{L}}$ takes into account the unit change (in $\mathrm{L}$ $\mathrm{mol}^{-1}$ ) and the molar concentration of water to obtain the dimensionless sorption constant [52].

Fig. 6 analyses the thermodynamic data and Table 5 summarizes the values of the relevant parameters. The endothermic behavior of U(VI) sorption on $\mathrm{R}-\mathrm{H}$ and $\mathrm{R}-\mathrm{NH}_{2}$ is confirmed by the positive value of its enthalpy changes: the values are in the same range $17.3-19.8 \mathrm{~kJ} \mathrm{~mol}^{-1}$. This behavior strongly contrasts with $\mathrm{R}-\mathrm{COOH}$ sorbent that exhibits an exothermic behavior with the enthalpy change being negative (i.e., -11 $\left.\mathrm{kJ} \mathrm{mol}^{-1}\right)$. Actually, the overall enthalpy change $\left(\Delta \mathrm{H}^{\circ}\right)$ is the balance between the energies engaged in bond breaking (i.e., consumed energy $=$ endothermic) and bond formation (i.e., released energy = 
Table 3

$\mathrm{U}(\mathrm{VI})$ sorption isotherms - Model parameters for the Langmuir, the Freundlich, and Sips equations.

\begin{tabular}{|c|c|c|c|c|c|c|c|c|c|c|c|c|c|c|c|}
\hline \multirow[t]{2}{*}{ Sorbent } & \multirow[t]{2}{*}{$\mathrm{T}\left({ }^{\circ} \mathrm{C}\right)$} & \multirow[t]{2}{*}{$\mathrm{q}_{\max , \exp }$} & \multicolumn{4}{|c|}{ Langmuir } & \multicolumn{4}{|c|}{ Freundlich } & \multicolumn{5}{|l|}{ Sips } \\
\hline & & & $\mathrm{q}_{\mathrm{m}, \mathrm{L}}$ & $\mathrm{b}_{\mathrm{L}}$ & $\mathrm{R}^{2}$ & AIC & $\mathrm{k}_{\mathrm{F}}$ & $\mathrm{n}_{\mathrm{F}}$ & $\mathrm{R}^{2}$ & AIC & $\mathrm{q}_{\mathrm{m}, \mathrm{s}}$ & $\mathrm{b}_{\mathrm{s}}$ & $\mathrm{n}_{\mathrm{F}}$ & $\mathrm{R}^{2}$ & AIC \\
\hline \multirow[t]{3}{*}{ R-H } & 20 & 1.057 & 1.306 & 7.32 & 0.988 & -52 & 1.31 & 2.56 & 0.955 & -39 & 1.276 & 8.53 & 0.954 & 0.989 & -47 \\
\hline & 30 & 1.116 & 1.353 & 8.59 & 0.986 & -47 & 1.40 & 2.67 & 0.955 & -37 & 1.320 & 10.2 & 0.949 & 0.986 & -42 \\
\hline & 40 & 1.166 & 1.362 & 11.4 & 0.978 & -39 & 1.47 & 2.87 & 0.954 & -34 & 1.319 & 15.1 & 0.923 & 0.976 & -34 \\
\hline \multirow[t]{3}{*}{$\mathrm{R}-\mathrm{COOH}$} & 20 & 0.535 & 0.601 & 11.1 & 0.971 & -46 & 0.585 & 3.60 & 0.929 & -43 & 0.572 & 19.5 & 0.841 & 0.971 & -41 \\
\hline & 30 & 0.513 & 0.585 & 9.40 & 0.963 & -44 & 0.559 & 3.39 & 0.933 & -42 & 0.566 & 12.7 & 0.907 & 0.963 & -39 \\
\hline & 40 & 0.499 & 0.576 & 8.42 & 0.957 & -43 & 0.542 & 3.27 & 0.931 & -42 & 0.558 & 11.0 & 0.915 & 0.956 & -38 \\
\hline \multirow[t]{3}{*}{$\mathrm{RNH}_{2}$} & 20 & 0.746 & 0.762 & 60.9 & 0.925 & -38 & 0.826 & 5.69 & 0.905 & -39 & 0.780 & 28.2 & 1.24 & 0.922 & -33 \\
\hline & 30 & 0.772 & 0.783 & 81.9 & 0.883 & -33 & 0.842 & 6.60 & 0.889 & -36 & 0.899 & 7.18 & 2.25 & 0.869 & -29 \\
\hline & 40 & 0.803 & 0.813 & 100.7 & 0.842 & -29 & 0.867 & 7.54 & 0.861 & -33 & 1.059 & 3.56 & 3.32 & 0.826 & -25 \\
\hline
\end{tabular}

$\mathrm{q}: \mathrm{mmol} \mathrm{U} \mathrm{g}^{-1}$, b: $\mathrm{L} \mathrm{mmol}^{-1}$.

Table 4

U(VI) Sorption isotherms - Model parameters for the Temkin equation.

\begin{tabular}{llllll}
\hline Sorbent & Temperature $\left({ }^{\circ} \mathrm{C}\right)$ & $\mathrm{A}_{\mathrm{T}}\left(\mathrm{L} \mathrm{mmol}^{-1}\right)$ & $\mathrm{b}_{\mathrm{T}}\left(\mathrm{kJ} \mathrm{mol}^{-1}\right)$ & $\mathrm{R}^{2}$ & AIC \\
\hline $\mathrm{R}-\mathrm{H}$ & 20 & 101.1 & 9.74 & 0.968 & -43 \\
& 30 & 126.7 & 9.94 & 0.966 & -40 \\
& 40 & 165.4 & 10.2 & 0.964 & -36 \\
$\mathrm{R}-$ & 20 & 142.8 & 21.3 & 0.956 & -43 \\
$\mathrm{COOH}$ & 30 & 115.7 & 22.1 & 0.952 & -42 \\
& 40 & 100.7 & 22.9 & 0.945 & -41 \\
$\mathrm{R}^{-\mathrm{NH}_{2}}$ & 20 & 2714 & 24.1 & 0.927 & -40 \\
& 30 & 16,080 & 30.3 & 0.880 & -35 \\
& 40 & 28,993 & 32.4 & 0.858 & -32 \\
\hline
\end{tabular}

exothermic) during the interaction of metal ions (including associated with sulfate in the case of uranyl) with the reactive groups. The contribution of different reactive groups (or numerous reactive groups) modulates the molecular interactions and the relevant energies involved in metal binding. The differences are also significantly marked considering the entropy changes: $\mathrm{R}-\mathrm{H}$ and $\mathrm{R}-\mathrm{NH}_{2}$ show $\Delta \mathrm{S}^{\circ}$ values much higher (165 and $192 \mathrm{~J} \mathrm{~mol}^{-1} \mathrm{~K}^{-1}$, respectively) than that reported for R-COOH (i.e., $74 \mathrm{~J} \mathrm{~mol}^{-1} \mathrm{~K}^{-1}$ ). The positive values of entropy changes, $\Delta \mathrm{S}^{\mathrm{o}}$, indicate an increase in randomness after metal sorption (at the solid/ liquid interface). The release of water molecules bound to metal ions or the exchange of metal ions with more mobile ions (initially present on the sorbent) may explain this increase of the randomness of the global system $[48,50,53]$. For the three sorbents, Gibbs free energy change $\left(\Delta \mathrm{G}^{\circ}\right)$ is negative and its absolute value increases with temperature: weakly for-R-COOH (between 33.0 and $34.5 \mathrm{~kJ} \mathrm{~mol}^{-1}$ ), a little more for $\mathrm{R}-\mathrm{H}$ (from 32.0 to $35.3 \mathrm{~kJ} \mathrm{~mol}^{-1}$ ) and for $\mathrm{R}-\mathrm{NH}_{2}$ (from 37.3 to $41.1 \mathrm{~kJ}$ $\mathrm{mol}^{-1}$ ). The negative value of free energy change means that U(VI) sorption is spontaneous. Zai [54] comments that when the Gibbs free energy ranges between -20 and $-80 \mathrm{~kJ} \mathrm{~mol}^{-1}$, the sorption is both physical and chemical. The sorption of uranyl ions onto selected sorbent is thus involving physical and chemical interactions. The absolute values of the enthalpy change $\left(\left|\Delta \mathrm{H}^{\circ}\right|\right)$ are strictly lower than the absolute values of $\left|\mathrm{T} \times \Delta \mathrm{S}^{\circ}\right|$; this means that the sorption is controlled by enthalpy changes rather than by entropy changes.

These thermodynamic data confirm the significant impact of the inserted moiety $\left(-\mathrm{COOH}\right.$ and $-\mathrm{NH}_{2}$ ) on the sorption behavior. The substituent changes the uptake kinetics, but also equilibrium and energetics of sorption. In order to compare the sorbents at the different temperatures, U(VI) sorption isotherms are reported for the three sorbents in Fig. AM13, at individual temperatures. The profiles are very comparable at $\mathrm{T}: 25^{\circ} \mathrm{C}$ and $35^{\circ} \mathrm{C}$ : the shape of the curves, the differences in initial affinities and saturation levels are respected. At T: $45{ }^{\circ} \mathrm{C}$, the initial slope of the curve for R-COOH is substantially decreased: while at lower temperatures R-COOH showed very favorable (almost irreversible profile), at the highest temperature, the favorability is decreased (the

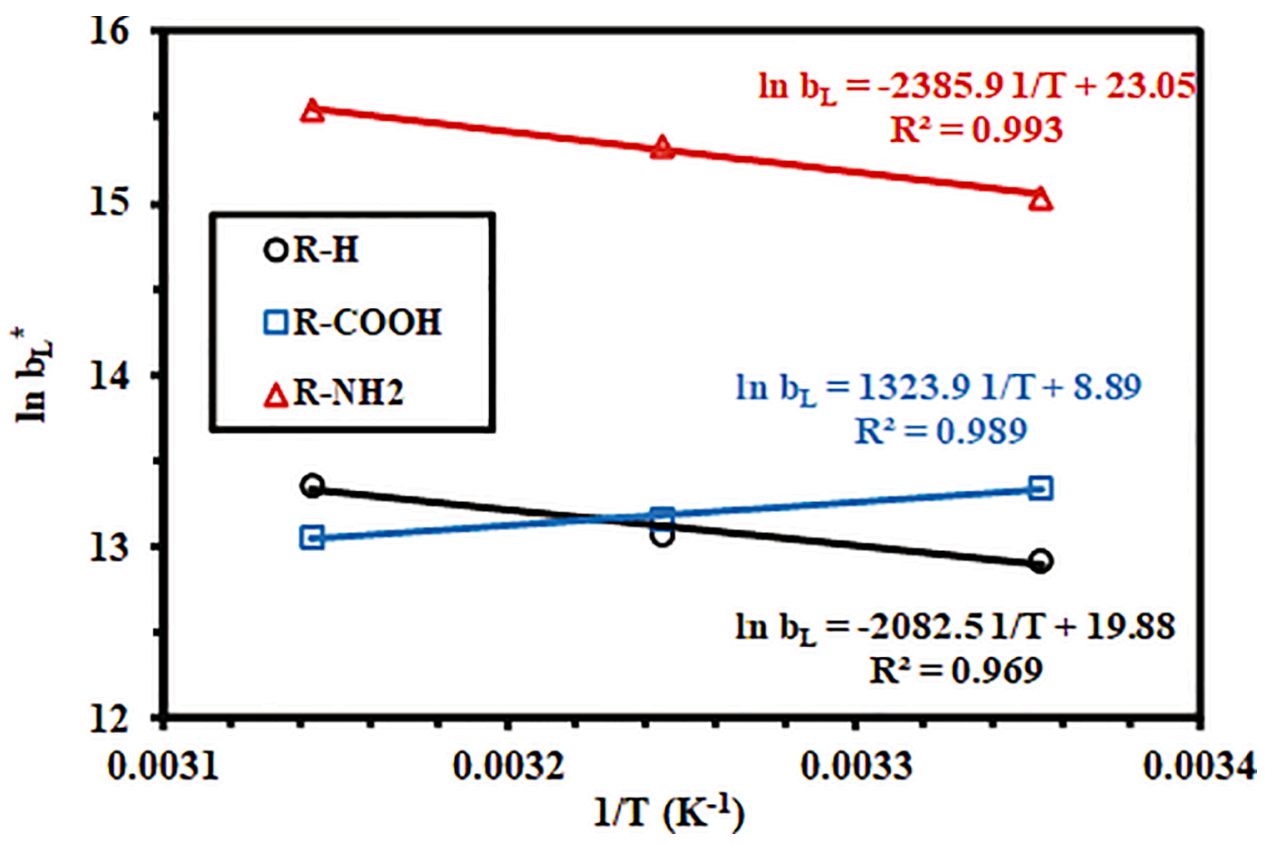

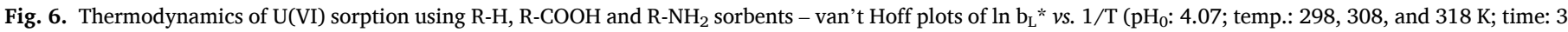
h; SD: $0.5 \mathrm{~g} \mathrm{~L}^{-1}$ ). 
Table 5

Thermodynamic parameters for U(VI) sorption.

\begin{tabular}{|c|c|c|c|c|c|c|}
\hline Sorbent & Temp. (K) & $\Delta \mathrm{H}^{\mathrm{o}}\left(\mathrm{kJ} \mathrm{mol}^{-1}\right)$ & $\Delta S^{o}\left(\mathrm{~J} \mathrm{~mol}^{-1} \mathrm{~K}^{-1}\right)$ & $\Delta \mathrm{G}^{\mathrm{o}}\left(\mathrm{kJ} \mathrm{mol}{ }^{-1}\right)$ & $\mathrm{T} \Delta \mathrm{S}^{\mathrm{o}}\left(\mathrm{kJ} \mathrm{mol}^{-1}\right)$ & $\mathrm{R}^{2}$ \\
\hline \multirow[t]{3}{*}{ R-H } & 298 & 17.31 & 165.3 & -31.96 & 49.28 & 0.969 \\
\hline & 308 & & & -33.61 & 50.93 & \\
\hline & 318 & & & -35.27 & 52.58 & \\
\hline \multirow[t]{3}{*}{ R-COOH } & 298 & -11.01 & 73.9 & -33.03 & 22.03 & 0.989 \\
\hline & 308 & & & -33.77 & 22.77 & \\
\hline & 318 & & & -34.51 & 23.50 & \\
\hline \multirow[t]{3}{*}{$\mathrm{R}-\mathrm{NH}_{2}$} & 298 & 19.84 & 191.6 & -37.30 & 57.13 & 0.993 \\
\hline & 308 & & & -39.21 & 59.05 & \\
\hline & 318 & & & -41.13 & 60.97 & \\
\hline
\end{tabular}

initial section of the curve overlaps with the R-H curve). This is directly correlated to the exothermic behavior of $\mathrm{U}(\mathrm{VI})$ sorption onto R-COOH: the sorption efficiency decreases at higher temperature.

The sorption capacities (under the same experimental conditions) were also compared at a single initial metal concentration (i.e., $\mathrm{C}_{0}: 1.05$ $\mathrm{mmol} \mathrm{U} \mathrm{g}^{-1}$ ), corresponding to the saturation plateau of the sorbents, for a larger range of temperatures (i.e., $25-55{ }^{\circ} \mathrm{C}$ ). Fig. AM14 shows the linear variation of the sorption capacity at equilibrium with the variation of the temperature: sorption capacity increases with temperature for $\mathrm{R}-\mathrm{H}$ and $\mathrm{R}-\mathrm{NH}_{2}$ contrary to R-COOH, consistently with reported endothermic/exothermic characteristics.

The isosteric heat of sorption $\left(\Delta \mathrm{H}_{\text {isost. }}, \mathrm{kJ} \mathrm{mol}^{-1}\right)$ was also calculated using the Clausius-Clapeyron equation [55], for different levels of metal loading $(x)$ on the sorbents:

$-\frac{\Delta H_{\text {isost }, x}}{R T^{2}}=\left[\frac{d \ln C_{e q, x}}{d T}\right]$

$\ln C_{e q, x}^{*}=\frac{\Delta H_{\text {isost }, x}}{R} \times \frac{1}{T}+K_{x}$

where $\mathrm{K}_{\mathrm{x}}$ is a constant. The concentrations $\mathrm{C}_{\mathrm{eq}, \mathrm{x}}{ }^{*}$ were calculated using the Sips equation based on fixed values of sorption capacities, at the different temperatures and were corrected to adopt molar units (mol $\mathrm{L}^{-1}$ ). The values were finally corrected from the molar concentration of water $(\times 1000 / 18=55.5)$ to obtain dimensionless concentrations. The isosteric heats of adsorption were then deduced from the slope of $\ln \mathrm{C}_{\mathrm{eq}}$, $x * v s$. the reciprocal of absolute temperature. Fig. AM15 shows that the sorbents have substantial differences in terms of heat of sorption. For the reference sorbent (i.e., R-H), the isosteric heat of sorption slightly increases (in the range 14.9-27.5 $\mathrm{kJ} \mathrm{mol}^{-1}$ ) when increasing metal loading. In the case of $\mathrm{R}-\mathrm{NH}_{2}$, the $\Delta \mathrm{H}_{\text {isost. }}$ strongly decreases from 86.3 $\mathrm{kJ} \mathrm{mol}^{-1}$ to around $20 \mathrm{~kJ} \mathrm{~mol}^{-1}$ (for metal loading 0.65-0.7 mmol U $\mathrm{g}^{-1}$ ) before increasing again at higher metal loading. For both R-H and $\mathrm{R}-\mathrm{NH}_{2}$, the isoteric heat of sorption is positive, contrary to $\mathrm{R}-\mathrm{COOH}$ (with increasing metal loading, $\Delta \mathrm{H}_{\text {isost. }}$ decreases from -3.8 to $-24.9 \mathrm{~kJ}$ $\mathrm{mol}^{-1}$ ). Guo et al. [55] reported that physical sorption corresponds to heat of sorption below $80 \mathrm{~kJ} \mathrm{~mol}^{-1}$. They also report that the heat of sorption remains constant with surface coverage: this is almost the case for R-H sorbent. On the opposite hand, strong variations in the isosteric heat of sorption reflect surface heterogeneities (probably associated to different mechanisms and sites of sorption) and/or lateral interactions between sorbed molecules at high metal loading [55].

Table 6 compares the sorption properties of U(VI) for different sorbents. Some sorbents, such as phosphorylated graphene oxide/chitosan composite [5], functionalized layered-double-hydroxides composites [56], picolylamine functionalized resin [57], modified polyacrylonitrile/silica composite [58], show outstanding sorption capacities (in the range $2-3.27 \mathrm{mmol} \mathrm{U} \mathrm{g}^{-1}$ ). However, the maximum sorption capacity of R-H allows ranking this sorbent among the most efficient for metal recovery from acidic solutions (i.e., at $\mathrm{pH} 4$ ).
Table 6

Comparison of $\mathrm{U}(\mathrm{VI})$ sorption capacities (equilibrium time, $\mathrm{q}_{\mathrm{m}, \mathrm{L}} \mathrm{mmol} \mathrm{U} \mathrm{g}^{-1}$ and $\mathrm{b}_{\mathrm{L}}, \mathrm{L} \mathrm{mmol}^{-1}$ ) using various sorbents.

\begin{tabular}{|c|c|c|c|c|c|}
\hline Sorbent & $\mathrm{pH}$ & Time & $\mathrm{q}_{\mathrm{m}, \mathrm{L}}$ & $\mathrm{b}_{\mathrm{L}}$ & Ref. \\
\hline Aminophosphonate-grafted chitosan & 4 & 120 & 1.35 & 6.64 & [3] \\
\hline Phosphonate-grafted oxide & 4 & 1440 & 1.06 & 33.3 & [4] \\
\hline Glutamine-grafted cellulose & 5 & 360 & 0.705 & 25.0 & [10] \\
\hline $\begin{array}{l}\text { Aminomethylphosphonic derivative of } \\
\text { chitosan }\end{array}$ & 5 & 360 & 0.485 & 21.4 & [61] \\
\hline Chitosan tripolyphosphate beads & 5 & 4320 & 0.995 & 4.52 & [37] \\
\hline Phosphonic Merrifield resin & 3.6 & 180 & 0.379 & 1.36 & [34] \\
\hline Phosphoramide-grafted SBA-15 & 5 & 20 & 1.31 & 18.3 & [32] \\
\hline Phosphonate-functionalized silica & 6.9 & 120 & 1.29 & 162 & {$[2]$} \\
\hline $\begin{array}{l}\text { Phosphorus-modified poly(styrene-co- } \\
\text { DVB) resin }\end{array}$ & 5 & 240 & 0.410 & 26.2 & [33] \\
\hline Bi-functionalized silica-magnetic NPs & 9 & 120 & 0.297 & - & [62] \\
\hline $\begin{array}{l}\text { Phosphorylated graphene oxide } \\
\text { chitosan composite }\end{array}$ & 5 & 15 & 3.27 & 23.1 & [5] \\
\hline Picolylamine functionalized resin & 5.3 & 120 & 2.31 & 164 & [57] \\
\hline Amidoxime-functionalized AC fiber & 5 & 2880 & 0.805 & 47.5 & [63] \\
\hline PEI-decorated polymer microbeads & 6 & 120 & 0.374 & 143 & [64] \\
\hline Modified PAN/Silica & 5 & 120 & 2.00 & 850 & [58] \\
\hline Eucalyptus wood biochar & 5.5 & 60 & 0.114 & 5.95 & [65] \\
\hline Fibrous anion exchanger & 2 & 15 & 0.04 & $\begin{array}{l}1.8 \times \\
10^{4}\end{array}$ & [66] \\
\hline $\begin{array}{l}\text { La-Al-carboxymethyl konjac } \\
\text { glucomannan } \mu \text { spheres }\end{array}$ & 5 & 900 & 0.51 & 20.9 & [67] \\
\hline $\begin{array}{l}\text { Nitrilotriacetate-modified algal } \\
\text { biomass }\end{array}$ & 5.5 & 120 & 1.51 & 11.8 & [68] \\
\hline Functionalized organo-volcanics & 5 & 240 & 1.68 & 3.43 & [69] \\
\hline Amidoxime-functionalized MCM-41 & 5 & 120 & 1.62 & 225 & [70] \\
\hline Functionalized LDH composites & 6 & 120 & 2.51 & 0.476 & [56] \\
\hline Functionalized Zn-MOF & 4 & 60 & 0.543 & 11.2 & [71] \\
\hline $\mathrm{NaOH}$ treated Citrus limon peel & 8 & 60 & 0.102 & 16.9 & [72] \\
\hline Aerobic activated sludge & 7 & 120 & 0.127 & 76.9 & [73] \\
\hline R-H & 4 & 120 & 1.31 & 7.32 & here \\
\hline $\mathrm{R}-\mathrm{COOH}$ & 4 & 120 & 0.601 & 11.1 & here \\
\hline $\mathrm{R}-\mathrm{NH}_{2}$ & 4 & 120 & 0.762 & 60.9 & here \\
\hline
\end{tabular}

\subsubsection{Summary on the interaction mechanisms involved in uranium} sorption

Different mechanisms may be involved in the binding of uranium, depending on the $\mathrm{pH}$ (in relation with the protonation/deprotonation of reactive groups and the speciation of uranyl species, under selected experimental conditions). Fig. AM8 clearly demonstrates that neutral uranyl sulfate predominates at $\mathrm{pH}$ below 3 (with coexistence of free uranyl ions and low amounts of uranyl sulfate anions), while at $\mathrm{pH} 4$, free uranyl species represent about $80 \%$ of total U(VI). Above $\mathrm{pH} 4.5$, the formation of hydrolyzed and polynuclear cationic species strongly changes the behavior of uranyl in solution.

In acidic solutions ( $\mathrm{pH}$ below 2), uranyl sorption may occur by electrostatic attraction of uranyl sulfate anions on protonated free amine groups, by coordination of free uranyl species onto protonated phosphonate groups and/or by ligand exchange of sulfate anion on neutral uranyl sulfate with phosphonate.

At $\mathrm{pH}$ around 3, phosphonate and amine groups are progressively deprotonated and more reactive for uranyl sulfate binding (and free 
amine groups); phosphonate groups are apparently more reactive for the binding of uranyl species compared with amine groups (based on FTIR observation).

At $\mathrm{pH}$ close to 4, the formation of polynuclear hydrolyzed species reduces the sorption of uranyl on the sorbent because of steric hindrance effects and difficulties in ligand exchange compared to lower $\mathrm{pH}$ values.

Actually, the effective binding mechanisms may be a contribution of these different mechanisms whose relative and respective importance depends on experimental conditions. In the case of uranyl binding on magnetic polyglycidylmethacrylate functionalized with aminophosphonic groups, Galhoum et al. [74] reported the strong interaction of uranyl species with several functional groups (based on FTIR and XPS analyses). A tetradentate complex is formed by ionic bond with a deprotonated oxygen atom of phosphonate moiety, the coordinate bonding with 2 nitrogen donors of amine groups and the coordination with one oxygen donor of $\mathrm{OH}$ group. Actually, this binding may be affected by the $\mathrm{pH}$ through the speciation of uranyl, but also the protonation/deprotonation of reactive groups, as reported above.

\subsubsection{Metal desorption and sorbent recycling}

Metal desorption and sorbent recycling are important steps in evaluating the potential of a sorbent for application in metal recovery and valorization, or for analytical use. Indeed, the desorption usually allows concentrating the metal for analytical application or for valorizing the metal (production of precipitated yellow cake in the case of uranium, for example). The recycling of the sorbent also contributes to the global competitiveness of the process. Several eluents can be used for desorbing $\mathrm{U}(\mathrm{VI})$ from loaded resins, including acidic solutions $[57,59]$ and sodium bicarbonate solutions [3,51]. Preliminary tests showed that $0.05 \mathrm{M}$ $\mathrm{NaHCO}_{3}$ solution (as well as $0.1 \mathrm{M} \mathrm{HCl}$ solution) allows the efficient and fast desorption of uranium from aminophosphonate resins: the desorption efficiency exceeds $98 \%$ within 90 min of contact. The ability of carbonate to form complexes with uranyl species (such as $\mathrm{UO}_{2}\left(\mathrm{CO}_{3}\right)_{2}^{2-}$, $\mathrm{UO}_{2}\left(\mathrm{CO}_{3}\right)_{3}^{4-}$, etc.) may explain the efficient elution of uranyl ions $[51,60]$. Kabay et al. [51] reported the possibility to reduce U(VI) to U (IV) for improving the desorption from a series of functionalized resins; $\mathrm{Na}_{2} \mathrm{CO}_{3}$ or $\mathrm{NH}_{4} \mathrm{CO}_{3}$ solutions successfully eluted U(VI) from a wide variety of resins. In the case of magnetic chitosan particles loaded with uranyl ions, $\mathrm{NaHCO}_{3}$ solution was preferred against calcium oxalate for metal elution [60].

Table 7 reports sorption and desorption steps repeated five times. The sorption and desorption efficiencies slightly decrease at each sorption stage. The loss in sorption efficiency does not exceed $8 \%$ at the fifth cycle and the three sorbents have roughly the same progressive loss in efficiency. The same loss in desorption efficiency is observed: from $97 \%$ to $99 \%$ of desorption at the first step, the desorption decreases to 93-94\% at the fifth cycle. The three sorbents show good metal desorption and remarkable stability in sorption for a minimum of five cycles of sorption/desorption, at least with synthetic pure solutions.

Fig. 2 also compares the FTIR spectra for the materials after five cycles of sorption and desorption. The analysis confirms that the general chemical structure of the sorbents has been roughly changed. The FTIR spectra of recycled sorbents remain very close to their raw form (initial

Table 7

Sorption efficiency (SE, \%) and desorption efficiency (DE, \%) for five successive cycles.

\begin{tabular}{|c|c|c|c|c|c|c|}
\hline \multirow[t]{2}{*}{ Cycle no. } & \multicolumn{2}{|l|}{ R-H } & \multicolumn{2}{|c|}{$\mathrm{R}-\mathrm{COOH}$} & \multicolumn{2}{|l|}{ R-NH ${ }_{2}$} \\
\hline & SE (\%) & DE (\%) & SE (\%) & DE (\%) & SE (\%) & DE (\%) \\
\hline 1 & $100 *$ & 97.92 & $100^{*}$ & 98.94 & $100 *$ & 97.29 \\
\hline 2 & 98.51 & 96.59 & 96.83 & 97.37 & 98.60 & 96.1 \\
\hline 3 & 97.13 & 95.33 & 95.07 & 96.18 & 96.86 & 94.73 \\
\hline 4 & 95.73 & 94.16 & 94.04 & 95.62 & 95.17 & 93.84 \\
\hline 5 & 93.72 & 92.77 & 92.16 & 94.39 & 94.07 & 93.01 \\
\hline
\end{tabular}

* Reference value for metal ion sorption efficiency (at first cycle). materials). However, in some cases, significant local changes are observed (depending on the material); making the spectra closer to the spectra obtained from uranyl-loaded sorbents. For example, for R-H sorbent, the main changes are identified: (a) the peak at $418.5 \mathrm{~cm}^{-1}$ appears close to the wavenumber observed for U-loaded material (at $416.5 \mathrm{~cm}^{-1}$, shifted from $404.0 \mathrm{~cm}^{-1}$ on raw material), and (b) the wide band with small peaks appearing between 2500 and $2200 \mathrm{~cm}^{-1}$.

\subsubsection{Testing on ore leachates}

Ore leaching allows recovering about $86 \%$ of uranium present in the ore $\left(1190 \mathrm{mg} \mathrm{kg}^{-1}\right)$. The concentration of uranium reaches $1026 \mathrm{mg} \mathrm{U}$ $\mathrm{L}^{-1}$. After $\mathrm{pH}$ control to 5 (for partially removing iron by precipitation), the loss of uranium is relatively limited: the residual concentration is $959 \mathrm{mg} \mathrm{U} \mathrm{L}{ }^{-1}$. Many elements are co-precipitated, with significant losses: $\mathrm{Si}(\approx 44 \%), \mathrm{Al}(\approx 39 \%)$, $\mathrm{Ca}(\approx 21 \%)$, $\mathrm{Ti}(\approx 15 \%), \mathrm{Na}(\approx 13 \%)$; in the case of iron, metal precipitation reaches $77 \%$. Considerable concentrations of elements remain in the solution: $\mathrm{Si}\left(\approx 44 \mathrm{~g} \mathrm{~L}^{-1}\right), \mathrm{Al}\left(\approx 22 \mathrm{~g} \mathrm{~L}^{-1}\right)$, $\mathrm{K}\left(\approx 6 \mathrm{~g} \mathrm{~L}^{-1}\right), \mathrm{Ti}\left(\approx 5 \mathrm{~g} \mathrm{~L}^{-1}\right), \mathrm{Na}\left(\approx 1.7 \mathrm{~g} \mathrm{~L}^{-1}\right), \mathrm{P}\left(\approx 1 \mathrm{~g} \mathrm{~L}^{-1}\right)$ and iron concentration reaches $716 \mathrm{mg} \mathrm{Fe} \mathrm{L}^{-1}$.

After adjusting the solution at $\mathrm{pH} 4$ (for optimum U(VI) sorption), the metal ions are poorly adsorbed on the three sorbents, except for U(VI).
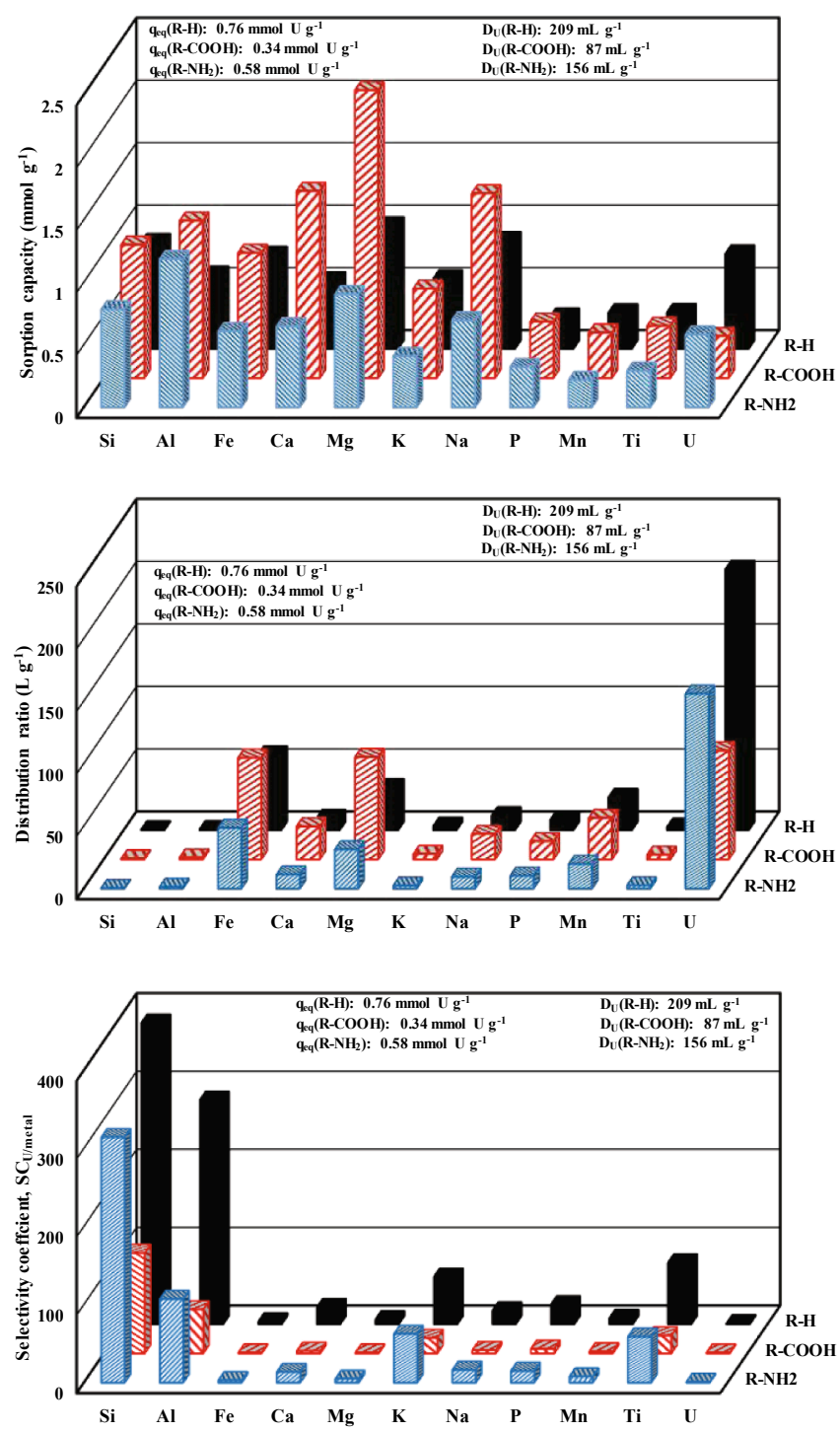

Fig. 7. Treatment of acidic leachate by sorption on R-H, R-COOH and $\mathrm{R}^{-\mathrm{NH}_{2}}$ (sorption efficiency (\%) for individual metals, $\mathrm{U}$ sorption capacity (mmol $\mathrm{U} \mathrm{g}^{-1}$ )

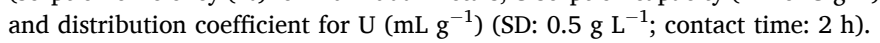


Fig. 7 summarizes the sorption performances for the different metals and for $\mathrm{R}-\mathrm{H}, \mathrm{R}-\mathrm{COOH}$ and $\mathrm{R}-\mathrm{NH}_{2}$. The presence of high concentrations of heavy metals induces the sorption of competitor metals with concentrations ranging between 0.22 and $2.3 \mathrm{mmol} \mathrm{g}^{-1}$, depending on the metal and the sorbent. For U(VI), the sorbents can be ranked according the series: R-H > R-NH $>$ > R-COOH; the sorption capacity of carboxylbearing derivative is more than halved compared with reference material (i.e., R-H). This ranking is consistent with the trends observed in the comparison of $\mathrm{q}_{\mathrm{m}}$ values in synthetic solutions (sorption isotherms). $\mathrm{R}$ $\mathrm{COOH}$ sorbent shows significantly higher affinities for alkali and alkaliearth metal ions (and to a lesser extent to $\mathrm{Si}, \mathrm{Al}$ and $\mathrm{Fe}$ ), compared with $\mathrm{R}-\mathrm{H}$ and $\mathrm{RNH}_{2}$ sorbents. R-COOH and $\mathrm{R}-\mathrm{H} / \mathrm{RNH}_{2}$ have complementary preferences in terms of sorption of selected metal ions.

The distribution ratio (i.e., D) allows minimizing the impact of the large differences in metal concentrations in the leachate for the evaluation of intrinsic sorption performances. The comparison of $\mathrm{D}$ values allows identifying the high efficiency of the sorbents for U(VI) (i.e., 87-209 $\mathrm{L} \mathrm{g}^{-1}$ ) compared with $\mathrm{Mg}(\mathrm{II})$ (i.e., 31-82 $\mathrm{L} \mathrm{g}^{-1}$ ), Fe(III) (i.e., 48-81 $\mathrm{L} \mathrm{g}^{-1}$ ) and $\mathrm{Mn}(\mathrm{II})$ (i.e., 20-33 $\mathrm{L} \mathrm{g}^{-1}$ ); for other elements the D ratios are even lower (i.e., below $20 \mathrm{~L} \mathrm{~g}^{-1}$ ). For $\mathrm{U}(\mathrm{VI})$, the sorbents are ranked according $\mathrm{R}-\mathrm{H}>\mathrm{R}-\mathrm{NH}_{2}>\mathrm{R}-\mathrm{COOH}$, while for the other metals significantly adsorbed R-COOH appears better than the other sorbents. The selectivity coefficient for U(VI) against other metal ions confirms the strong preference of the aminophosphonate-based sorbents for U(VI) against $\mathrm{Si}(\mathrm{IV})>\mathrm{Al}(\mathrm{III})>\mathrm{Ti}(\mathrm{IV})>\mathrm{K}(\mathrm{I})$, despite the huge excess of these metal ions. R-COOH has systematically a much lower selectivity for $\mathrm{U}$ (VI) compared with $\mathrm{R}-\mathrm{H}$ and $\mathrm{R}-\mathrm{NH}_{2}$ (which have comparable profiles, with a higher efficiency in uranyl separation from silicon and aluminum for R-H). The lowest selectivity for U(VI) is found for Fe(III) (i.e., 1-3), $\mathrm{Mg}$ (II) (i.e., 1-6), Mn(II) (i.e., 2-8). Actually, for R-H sorbent (the most selective of the three sorbents), under these experimental conditions (treatment of leachate), the preference for $\mathrm{U}(\mathrm{VI})$ increases according: $\mathrm{Fe}$ (III) $>\mathrm{Mg}(\mathrm{II})>\mathrm{Mn}(\mathrm{II}) \gg \mathrm{Na}(\mathrm{I})>\mathrm{Ca}(\mathrm{II})>\mathrm{P}(\mathrm{V}) \gg \mathrm{K}(\mathrm{I}) \gg \mathrm{Ti}(\mathrm{IV}) \gg>\mathrm{Al}$ (III) $>>>$ Si(IV).

The global performance is comparable for $\mathrm{R}-\mathrm{H}$ and $\mathrm{R}-\mathrm{NH}_{2}$ (little higher for R-H), R-COOH has a relatively higher affinity for alkali and alkali-earth elements; this resin is characterized by a lower selectivity for $U$ against other selected metal ions.

\section{Conclusion}

In this study, three different $\alpha$-aminophosphonate chelating sorbents were synthesized by one-pot reaction of salicyladedyde with a series of phenylamine-based compounds (bearing different substituents: aniline for $\mathrm{R}-\mathrm{H}$, anthranilic for R-COOH and O-phenylene diamine for $\mathrm{R}^{-\mathrm{NH}_{2}}$ ) in the presence of triphenylphosphine. The sorbents (R-H, R-COOH, and R$\mathrm{NH}_{2}$, respectively) were characterized by CHNP analysis, FTIR, ${ }^{1} \mathrm{H}$ NMR and ${ }^{31} \mathrm{P}$ NMR, XPS, $\mathrm{pH}$ PZC, DLS, zeta potential analysis, and TGA for confirmation of grafting mechanism and for identifying potential reactive groups. FTIR analysis confirms the contribution of phosphonate, amine $\left(\mathrm{R}-\mathrm{NH}_{2}\right)$ and carboxylic $(\mathrm{R}-\mathrm{COOH})$ groups in uranium binding, with variable relative importance depending on the sorbent.

Uranyl is efficiently sorbed at $\mathrm{pH} 4$, the optimal initial $\mathrm{pH}$; though the $\mathrm{pH}$ decreases around $\mathrm{pH} 3.4$ during metal sorption. The $\mathrm{pH}$ variation is correlated to the $\mathrm{pH}_{\mathrm{PZC}}$ values of the sorbents. Uptake kinetics are fitted using the PFORE, the PSORE and the RIDE models; though the different models give very close simulations of the kinetic profiles, the PFORE gives a little better fit.

Sorption isotherms show an asymptotic trend that is correctly fitted by the Langmuir equation; the saturation plateaus show maximum sorption capacities (monolayer coverage from Langmuir equation, $\mathrm{q}_{\mathrm{m}, \mathrm{L}}$ ) at $25^{\circ} \mathrm{C}$ close to $1.31 \mathrm{mmol} \mathrm{U} \mathrm{g}^{-1}, 0.601 \mathrm{mmol} \mathrm{U} \mathrm{g}^{-1}$ and $0.762 \mathrm{mmol} \mathrm{U}$ $\mathrm{g}^{-1}$ for R-H, R-COOH and R-NH ${ }_{2}$, respectively. The influence (positive/ negative) of the substituents (i.e., $-\mathrm{H},-\mathrm{COOH},-\mathrm{NH}_{2}$ ) appears not only on the saturation value but also on the affinity coefficient (i.e., $b_{\mathrm{L}}$ value) and on thermodynamics. Indeed, while U(VI) sorption is endothermic for $\mathrm{R}-\mathrm{H}$ and $\mathrm{R}-\mathrm{NH}_{2}, \mathrm{R}-\mathrm{COOH}$ shows an exothermic uptake of the metal. The reaction is spontaneous (negative value of the free Gibbs energy change) and controlled by enthalpy (rather than entropy). The positive value (lowest for $\mathrm{R}-\mathrm{COOH}$ ) of the entropy changes means that the randomness of the system increases during sorption (release of hydration water, exchange of counter ions at the surface of the sorbent, changes in the speciation of the metal ions in solution).

Uranium can be efficiently regenerated from loaded sorbents using $0.5 \mathrm{M}$ solutions of $\mathrm{NaHCO}_{3}$ and the sorbents can be reused for at least five sorption/desorption cycles with a limited loss of sorption and desorption efficiencies (less than $8 \%$, at the fifth cycle).

Finally, these sorbents were successfully tested for uranium recovery from acidic liquor produced by sulfuric acid treatment of Egyptian ore from El-Sella area showing that despite its complex composition the sorbents maintained relatively high sorption capacities (maximum sorption capacities being reduced by $21 \%$ for $\mathrm{R}-\mathrm{H}, 33 \%$ for $\mathrm{R}-\mathrm{COOH}$ and $13 \%$ for $\mathrm{R}-\mathrm{NH}_{2}$ ).

Resins bearing $\alpha$-aminophosphonate moieties are very efficient for $\mathrm{U}$ (VI) binding and recovery. The sorption properties can be modulated by selecting the substituents to be inserted on the backbone (and then choosing appropriately the phenylamine-based precursor, Table AM3). Actually, the simplest precursor (aniline for R-H) shows the highest sorption capacity for U(VI), while phenylenediamine allows introducing supplementary amine groups that increases the favorability of uranyl sorption at low concentration. Surprisingly, the introduction of carboxylic groups (anthranilic precursor) completely changes the thermodynamic behavior of the resin.

\section{Declaration of Competing Interest}

The authors declare that they have no known competing financial interests or personal relationships that could have appeared to influence the work reported in this paper.

\section{Acknowledgements}

This work was financially supported by Nuclear Materials Authority (Egypt), Institut Français d'Egypte (Ministère des Affaires Etrangères, MAE), and Ministère de l'Enseignement Supérieur et de la Recherche, MESR), Chinese Academy of Sciences President's International Fellowship Initiative (Grant No. 122111WGZJTPYJY20180050), CAS-TWAS Centre of Excellence, Innovation Academy for Green Manufacture, Chinese Academy of Sciences (IAGM-2019-A06) and National Natural Science Foundation of China (Nos. 21878314, 21878292). Authors thank Dr. Mai S. Maiz, (Faculty of Science, Menoufia Univ., Egypt) for her technical support. Special dedication to the memory of Prof. Ahmed Donia.

\section{Appendix A. Supplementary data}

Supplementary data to this article can be found online at https://doi. org/10.1016/j.cej.2020.127830.

\section{References}

[1] Y.i. Xie, C. Chen, X. Ren, X. Wang, H. Wang, X. Wang, Emerging natural and tailored materials for uranium-contaminated water treatment and environmental remediation, Prog. Mater Sci. 103 (2019) 180-234.

[2] L.-Y. Yuan, Y.-L. Liu, W.-Q. Shi, Y.-L. Lv, J.-H. Lan, Y.-L. Zhao, Z.-F. Chai, High performance of phosphonate-functionalized mesoporous silica for U(VI) sorption from aqueous solution, Dalton Trans. 40 (28) (2011) 7446-7453.

[3] E.A. Imam, I. El-Tantawy El-Sayed, M.G. Mahfouz, A.A. Tolba, T. Akashi, A. A. Galhoum, E. Guibal, Synthesis of $\alpha$-aminophosphonate functionalized chitosan sorbents: Effect of methyl vs phenyl group on uranium sorption, Chem. Eng. J. 352 (2018) 1022-1034.

[4] X. Liu, J. Li, X. Wang, C. Chen, X. Wang, High performance of phosphatefunctionalized graphene oxide for the selective adsorption of U(VI) from acidic solution, J. Nucl. Mater. 466 (2015) 56-64. 
[5] Y.W. Cai, C.F. Wu, Z.Y. Liu, L.J. Zhang, L.H. Chen, J.Q. Wang, X.K. Wang, S. T. Yang, S. Wang, Fabrication of a phosphorylated graphene oxide-chitosan composite for highly effective and selective capture of U(VI), Environ. Sci. Nano 4 (2017) 1876-1886.

[6] É.C. Avelar, C.L.G. Alvarenga, G.P.S. Resende, C.A. Morais, M.B. Mansur, Modeling of the solvent extraction equilibrium of uranium(VI) sulfate with Alamine 336 Braz. J. Chem. Eng. 34 (1) (2017) 355-362.

[7] Z. Zhu, Y. Pranolo, C.Y. Cheng, Uranium recovery from strong acidic solutions by solvent extraction with Cyanex 923 and a modifier, Miner. Eng. 89 (2016) 77-83.

[8] K. Inoue, H. Kawakita, K. Ohto, T. Oshima, Adsorptive removal of uranium and thorium with a crosslinked persimmon peel gel, J. Radioanal. Nucl. Chem. 267 (2) (2006) 435-442.

[9] K. Inoue, S. Alam, Refining and Mutual Separation of Rare Earths Using Biomass Wastes, JOM 65 (10) (2013) 1341-1347.

[10] M.N. El-Bohy, Y.K. Abdel-Monem, K.A. Rabie, N.M. Farag, M.G. Mahfouz, A. A. Galhoum, E. Guibal, Grafting of arginine and glutamic acid onto cellulose for enhanced uranyl sorption, Cellulose 24 (3) (2017) 1427-1443.

[11] B. Mahanty, P.K. Mohapatra, Highly efficient separation of thorium from uranium in nitric acid feeds by solid phase extraction using Aliquat 336, Sep. Purif. Technol. 237 (2020).

[12] S.S. Lee, W.L. Li, C. Kim, M. Cho, J.G. Catalano, B.J. Lafferty, P. Decuzzi, J. D. Fortner, Engineered manganese oxide nanocrystals for enhanced uranyl sorption and separation, Environ. Sci. Nano 2 (2015) 500-508.

[13] R.G. Pearson, Acids and bases 151 (1966) 172-177.

[14] S.D. Alexandratos, X. Zhu, Polymer-supported aminomethylphosphinate as a ligand with a high affinity for U(VI) from phosphoric acid solutions: Combining variables to optimize ligand-ion communication, Solvent Extr. Ion Exch. 34 (2016) 290-295.

[15] X. Zhu, S.D. Alexandratos, Development of a new ion-exchange/coordinating phosphate ligand for the sorption of $\mathrm{U}(\mathrm{VI})$ and trivalent ions from phosphoric acic solutions, Chem. Eng. Sci. 127 (2015) 126-132.

[16] A.A. Galhoum, E.A. Elshehy, D.A. Tolan, A.M. El-Nahas, T. Taketsugu, K. Nishikiori, T. Akashi, A.S. Morshedy, E. Guibal, Synthesis of polyaminophosphonic acid-functionalized poly(glycidyl methacrylate) for the efficient sorption of La(III) and Y(III), Chem. Eng. J. 375 (2019) 121932-121948.

[17] M.F. Cheira, Synthesis of aminophosphonate-functionalised $\mathrm{ZnO} /$ polystyrenebutadiene nanocomposite and its characteristics for uranium adsorption from phosphoric acid, Int. J. Environ. Anal. Chem. (2020), https://doi.org/10.1080/ 03067319.03062019.01686493.

[18] K. Vaaramaa, S. Pulli, J. Lehto, Effects of $\mathrm{pH}$ and uranium concentration on the removal of uranium from drinking water by ion exchange, Radiochim. Acta 88 (2000) 845-849.

[19] M. Ciopec, L. Lupa, A. Negrea, C.M. Davidescu, A. Popa, P. Negrea, M. Motoc, D. David, D. Kaycsa, Kinetic and thermodynamic studies regarding Cu(II) ions removal from aqueous solution by poly(styrene-divinylbenzene)-supported aminophosphonic acids, Rev. Chim. 63 (2012) 49-53.

[20] A. Popa, R. Ene, D. Visinescu, E.S. Dragan, G. Ilia, S. Iliescu, V. Parvulescu, Transitional metals immobilized by coordination on aminophosphonate functionalized copolymers and their catalytic properties, J. Mol. Catal. A: Chem. 408 (2015) 262-270.

[21] B. Maranescu, A. Popa, L. Lupa, V. Maranescu, A. Visa, Use of chitosan complex with aminophosphonic groups and cobalt for the removal of $\mathrm{Sr}^{2+}$ ions, Sep. Sci. Technol. 53 (2018) 1058-1064.

[22] Z. Marczenko, Separation and Spectrophotometric Determination of Elements, 2nd, Ed. ed., Ellis Horwood, Chichester, UK, 1986, p. 678.

[23] H.N.A. Hassan, M.E.M. Hassouna, Simultaneous microdetermination of carbon, hydrogen, phosphorus and chlorine or bromine in organic compounds and some pharmaceutical preparations, Egyptian J. Pharm. Sci. 34 (1993) 445-454.

[24] M.E.M. Hassouna, H.N.A. Hassan, One step oxygen flask-spectrophotometric method for the micro and submicro-determination of phosphorus in organophosphorus compounds, Egyptian J. Chem. 37 (1994) 615-626.

[25] M.V. Lopez-Ramon, F. Stoeckli, C. Moreno-Castilla, F. Carrasco-Marin, On the characterization of acidic and basic surface sites on carbons by various techniques, Carbon 37 (1999) 1215-1221.

[26] T.M. Ibrahim, K.G. Ali, I.M. Gaafar, S.M. Masoud, S.A. Omer, H.A. Shahin, M.M. Haridy, E.M. Aly, M. Biomy, A. Abdel Gawad, et al., Extensive studies on G. El-Sella Shear zone South Eastern Desert, Egypt. , in, Nuclear Materials Authority, Cairo, Egypt, 2005.

[27] A.A. Galhoum, Studies on Extraction of Uranium and Some Rare Earth Elements from El-Sella Area Using Chelating Resins with Amine and Amino Acid Functionality, in: Faculty of Sciences, Ain Shams University, Cairo, Egypt, 2015.

[28] L. Shapiro, Rapid analysis of silicate, carbonate, and phosphate rocks, in: Bulletin, U.S. Geol. Surv. Bull., Vol. 76, pIII, Report Number 1401, 1975, pp. 88.

[29] W. Davies, W. Gray, A rapid and specific titrimetric method for the precise determination of uranium using iron(II) sulphate as reductant, Talanta 11 (1964) 1203-1211.

[30] K.J. Mathew, S. Buerger, S. Vogt, P. Mason, M.E. Morales-Arteaga, U.I. Narayanan, Uranium assay determination using Davies and Gray titration: an overview and implementation of GUM for uncertainty evaluation, J. Radioanal. Nucl. Chem. 282 (2009) 939-944.

[31] A.R. Elsalamouny, O.A. Desouky, S.A. Mohamed, A.A. Galhoum, E. Guibal, Evaluation of adsorption behavior for $\mathrm{U}(\mathrm{VI})$ and $\mathrm{Nd}(\mathrm{III})$ ions onto fumarated polystyrene microspheres, J. Radioanal. Nucl. Chem. 314 (2017) 429-437.

[32] Y. Ren, R. Yang, L. Shao, H. Tang, S. Wang, J. Zhao, J. Zhong, C. Kong, The removal of aqueous uranium by SBA-15 modified with phosphoramide: a combined experimental and DFT study, RSC Adv. 6 (2016) 68695-68704.
[33] Q. Cao, Y. Liu, X. Kong, L. Zhou, H. Guo, Synthesis of phosphorus-modified poly (styrene-co-divinylbenzene) chelating resin and its adsorption properties of uranium(VI), J. Radioanal. Nucl. Chem. 298 (2013) 1137-1147.

[34] N. Ferrah, O. Abderrahim, M.A. Didi, D. Villemin, Sorption efficiency of a new sorbent towards uranyl: phosphonic acid grafted Merrifield resin, J. Radioanal. Nucl. Chem. 289 (2011) 721-730.

[35] A.M. Borreguero, M.M. Velencoso, J.F. Rodriguez, A. Serrano, M.J. Carrero, M. J. Ramos, Synthesis of aminophosphonate polyols and polyurethane foams with improved fire retardant properties, J. Appl. Polym. Sci. 136 (2019).

[36] M.O. Abd El-Magied, A.A. Galhoum, A.A. Atia, A.A. Tolba, M.S. Maize, T. Vincent, E. Guibal, Cellulose and chitosan derivatives for enhanced sorption of erbium(III), Colloids Surf., A 529 (2017) 580-593.

[37] M.K. Sureshkumar, D. Das, M.B. Mallia, P.C. Gupta, Adsorption of uranium from aqueous solution using chitosan-tripolyphosphate (CTPP) beads, J. Hazard. Mater. 184 (2010) 65-72.

[38] J. Coates, Interpretation of Infrared Spectra, A Practical Approach, in: Encyclopedia of Analytical Chemistry, John Wiley \& Sons, Ltd., 2006, pp. 1-23.

[39] A. Chandrasekar, T.K. Ghanty, C. Rao, M. Sundararajan, N. Sivaraman, Strong influence of weak hydrogen bonding on actinide-phosphonate complexation: accurate predictions from DFT followed by experimental validation, Phys. Chem. Chem. Phys. 21 (2019) 5566-5577.

[40] P. Van der Veken, I. El Sayed, J. Joossens, C.V. Stevens, K. Augustyns, A. Haemers, Lewis acid catalyzed synthesis of N-protected diphenyl 1-aminoalkylphosphonates, Synthesis-Stuttgart 4 (2005) 634-638.

[41] Y. Liu, Y. Zhang, Z.H. Cao, M. Peng, Z.P. Fang, Synthesis of novel poly (aminophosphonate ester)s flame retardants and their applications in EVA copolymer, Polym. Adv. Technol. 24 (2013) 197-203.

[42] D.H. Ripin, E. D.A., pKa's of inorganic and Oxo-acids, in, 2005.

[43] R. Williams, pKa data (compiled by R. Williams), http://www.chem.wisc.edu/ areas/reich/pkatable/pKa_compilation-1-Williams.pdf, Accessed: 4/6/2017.

[44] Y. Marcus, Ion Properties, Marcel Dekker Inc, New York, NY, 1997, p. 259.

[45] L.D. Michelsen, P.G. Gideon, G. G.P., E.G. Pace, L.H. Kutal, Removal of Soluble Mercury from Wastewaters by Complexing Techniques: Bulletin No.74, in: Office of Water Research and Technology. U.S. Department of Industry (Ed.), Virginia Water Resources Research Center, Blacksburg, VA, USA, 1975, pp. 173.

[46] P. Hermann, I. Lukes, Complexing properties of phosphonodipeptides containing aminomethylphosphonic acid, J. Chem. Soc., Dalton Trans. (1995) 2605-2610.

[47] W.H. Cheung, Y.S. Szeto, G. McKay, Intraparticle diffusion processes during acid dye adsorption onto chitosan, Bioresour. Technol. 98 (2007) 2897-2904.

[48] M.F. Cheira, H.I. Mira, A.K. Sakr, S.A. Mohamed, Adsorption of U(VI) from acid solution on a low-cost sorbent: equilibrium, kinetic, and thermodynamic assessments, Nucl. Sci. Tech. 30 (2019).

[49] C. Tien, Adsorption Calculations and Modeling, Butterworth-Heinemann, Newton, MA, 1994, p. 243.

[50] M.A. Abostate, Y. Saleh, H. Mira, M. Amin, M. Al Kazindar, B.M. Ahmed, Characterization, kinetics and thermodynamics of biosynthesized uranium nanoparticles (UNPs), Artif. Cells Nanomed. Biotechnol. 46 (2018) 147-159.

[51] N. Kabay, M. Demircioglu, S. Yayli, E. Gunay, M. Yuksel, M. Saglam, M. Streat, Recovery of uranium from phosphoric acid solutions using chelating ion-exchange resins, Ind. Eng. Chem. Res. 37 (1998) 1983-1990.

[52] E.C. Lima, A. Hosseini-Bandegharaei, J.C. Moreno-Piraján, I. Anastopoulos, A critical review of the estimation of the thermodynamic parameters on adsorption equilibria. Wrong use of equilibrium constant in the Van't Hoof equation for calculation of thermodynamic parameters of adsorption, J. Mol. Liq. 273 (2019) $425-434$.

[53] C. Escudero-Oñate, I. Villaescusa, The Thermodynamics of Heavy Metal Sorption onto Lignocellulosic Biomass, in: H.E.-.D.M. Saleh, R.F. Aglan (Eds.), Heavy Metals, IntechOpen, London, UK, 2018, pp. 235-251.

[54] Q.-Z. Zhai, Use of SBA-15 ordered nano mesoporous silica for removal of copper(II) from aqueous media: Studies on equilibrium, isotherm, kinetics and thermodynamics, J. Environ. Chem. Eng. 7 (2019). Art. N 103069.

[55] N. Guo, X. Lv, Q. Li, T. Ren, H. Song, Q. Yang, Removal of hexavalent chromium from aqueous solution by mesoporous $\alpha$-FeOOH nanoparticles: Performance and mechanism, Microporous Mesoporous Mater. 299 (2020), 110101.

[56] J. Zhu, Q. Liu, J. Liu, R. Chen, H. Zhang, R. Li, J. Wang, Ni-Mn LDH-decorated 3D Fe-inserted and N-doped carbon framework composites for efficient uranium(VI) removal, Environ. Sci. Nano 5 (2018) 467-475.

[57] S. Liu, Y. Yang, T. Liu, W. Wu, Recovery of uranium(VI) from aqueous solution by 2-picolylamine functionalized polystyrene-co-maleic anhydride) resin, J. Colloid Interface Sci. 497 (2017) 385-392.

[58] G. Bayramoglu, M.Y. Arica, MCM-41 silica particles grafted with polyacrylonitrile: Modification in to amidoxime and carboxyl groups for enhanced uranium removal from aqueous medium, Microporous Mesoporous Mater. 226 (2016) 117-124.

[59] H. Parab, S. Joshi, N. Shenoy, R. Verma, A. Lali, M. Sudersanan, Uranium removal from aqueous solution by coir pith: equilibrium and kinetic studies, Bioresour. Technol. 96 (2005) 1241-1248.

[60] L.C.B. Stopa, M. Yamaura, Uranium removal by chitosan impregnated with magnetite nanoparticles: adsorption and desorption, Int. J. Nucl. Energy Sci. Technol. 5 (2010) 283-289.

[61] A.R. Elsalamouny, O.A. Desouky, S.A. Mohamed, A.A. Galhoum, E. Guibal, Uranium and neodymium biosorption using novel chelating polysaccharide, Int. J. Biol. Macromol. 104 (2017) 963-968.

[62] X.T. Chen, L.F. He, R.Z. Liu, C. Zhang, B. Liu, Y.P. Tang, Effective uranium(VI) sorption from alkaline media using bi-functionalized silica-coated magnetic nanoparticles, RSC Adv. 5 (2015) 56658-56665. 
[63] X. Lu, D. Zhang, A. Tesfay Reda, C. Liu, Z. Yang, S. Guo, S. Xiao, Y. Ouyang, Synthesis of amidoxime-grafted activated carbon fibers for efficient recovery of uranium(VI) from aqueous solution, Ind. Eng. Chem. Res. 56 (2017) 11936-11947.

[64] G. Bayramoglu, M.Y. Arica, Polyethylenimine and tris(2-aminoethyl)amine modified p(GA-EGMA) microbeads for sorption of uranium ions: equilibrium, kinetic and thermodynamic studies, J. Radioanal. Nucl. Chem. 312 (2017) 293-303.

[65] V. Mishra, M.K. Sureshkumar, N. Gupta, C.P. Kaushik, Study on sorption characteristics of uranium onto biochar derived from eucalyptus wood, Water Air Soil Pollut., 228 (2017) Art. $\mathrm{N}^{\circ} 309$.

[66] V.F. Sazonova, O.V. Perlova, N.A. Perlova, A.P. Polikarpov, Sorption of uranium (VI) compounds on fibrous anion exchanger surface from aqueous solutions, Colloid J. 79 (2017) 270-277.

[67] S. Sun, X. Lin, L. Wu, X. Luo, Sorption of uranium(VI) by La-Al-carboxymethyl konjac glucomannan microsphere sorbent, J. Radioanal. Nucl. Chem. 314 (2017) 1039-1050.

[68] G. Bayramoglu, A. Akbulut, I. Acikgoz-Erkaya, M.Y. Arica, Uranium sorption by native and nitrilotriacetate-modified Bangia atropurpurea biomass: kinetics and thermodynamics, J. Appl. Phycol. 30 (2018) 649-661.

[69] U.H. Kaynar, U. Hicsonmez, S.C. Kaynar, S. Kocak, Sorption of uranium(VI) from aqueous solutions by DEEA organo-volcanic: isotherms, kinetic and thermodynamic studies, Nucl. Sci. Tech. 29 (30) (2018) 1-11.
[70] R. Khamirchi, A. Hosseini-Bandegharaei, A. Alahabadi, S. Sivamani, A. RahmaniSani, T. Shahryari, I. Anastopoulos, M. Miri, H.N. Tran, Adsorption property of BrPADAP-impregnated multiwall carbon nanotubes towards uranium and its performance in the selective separation and determination of uranium in different environmental samples, Ecotoxicol. Environ. Saf. 150 (2018) 136-143.

[71] R. Liu, Z.-Q. Wang, Q.-Y. Liu, F. Luo, Y.-L. Wang, A zinc MOF with carboxylate oxygen-functionalized pore channels for uranium(VI) sorption, Eur. J. Inorg. Chem. 2019 (5) (2019) 735-739.

[72] E. Sabanovic, T. Muhic-Sarac, M. Nuhanovic, M. Memic, Biosorption of uranium (VI) from aqueous solution by Citrus limon peels: kinetics, equilibrium and batch studies, J. Radioanal. Nucl. Chem. 319 (2019) 425-435.

[73] X.L. Wang, Y. Li, J. Huang, Y.Z. Zhou, D.B. Liu, J.T. Hu, B.L. Li, Y. Ke, Efficiency and mechanism of sorption of low concentration uranium in water by powdery aerobic activated sludge, Ecotoxicol. Environ. Saf. 180 (2019) 483-490.

[74] A.A. Galhoum, W.H. Eisa, I.E.-T. El-Sayed, A.A. Tolba, Z.A. Shalaby, S.

I. Mohamady, S.S. Muhammad, S.S. Hussein, T. Akashi, E. Guibal, A new route for manufacturing poly(aminophosphonic)-functionalized poly(glycidyl methacrylate)-magnetic nanocomposite - Application to uranium sorption from ore leachate, Environ. Pollut. 264 (2020), 114797, https://doi.org/10.1016/j. envpol.2020.114797. 